Design of the Cooling Systems for the Multiplicity and Vertex Detector

J. D. Bernardin

B. Cunningham

DISTRIBUTION OF THIS DOCUMENT IS INUMATED 


\section{DISCLAMVIER}

Portions of this docoment may be illegibie in electronic irosge products. Imoges are produced from the best available original docomentert 


\section{DISCLAIMER}

This report was prepared as an account of work sponsored by an agency of the United States Government. Neither the United States Government nor any agency thereof, nor any of their employees, make any warranty, express or implied, or assumes any legal liabifity or responsibility for the accuracy, completeness, or usefulness of any information, apparatus, product, or process disclosed, or represents that its use would not infringe privately owned rights. Reference herein to any specific commercial product, process, or service by trade name, trademark, manufacturer, or otherwise does not necessarily constitute or imply its endorsement, recommendation, or favoring by the United States Government or any agency thereof. The views and opinions of authors expressed herein do not necessar. ily state or reflect those of the United States Government or any agency thereof. 


\section{TABLE OF CONTENTS}

Abstract-- 1

1. MVD Overview and Electronics Cooling Strategies-- 1

2. Design Procedure - 6

3. Cooling System Designs ---

3.1. Primary Air Cooling System for Multichip Modules (MCMs)-

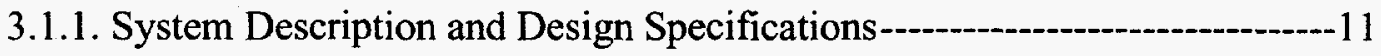

3.1.2. Components and Costs List---17

3.1.3. Safety Measures---25

3.1.4. System Operation ---_-

3.2. Secondary Air Cooling System for Enclosure --

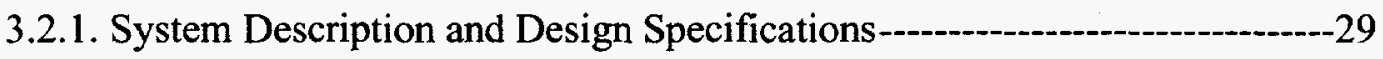

3.2.2. Components and Costs List---_-

3.2.3. Safety Measures--48

3.2.4. System Operation --_-

3.3. Liquid Cooling System for Low Dropout Voltage Regulators (LDOs)---_-a----50

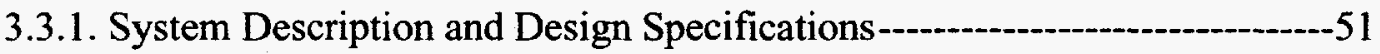

3.3.2. Components and Costs List--.-_-

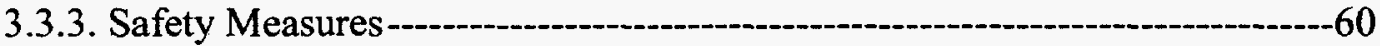

3.3.4. System Operation --

3.4. Action Items - -63

References --1-1-

List of Vendors--

Appendix - Design/Assembly Problem Summary - 


\title{
Design of the Cooling Systems for the Multiplicity and Vertex Detector
}

by

J. D. Bernardin and R. Cunningham

\begin{abstract}
This report presents the final mechanical designs of the cooling systems for the Multiplicity and Vertex Detector (MVD). In particular, the design procedure and layouts are discussed for two different air cooling systems for the multichip modules and MVD enclosure, and a liquid cooling system for the low dropout voltage regulators. First of all, experimental prototype cooling system test results used to drive the final mechanical designs are summarized and discussed. Next, the cooling system requirements and design calculation for the various subsystem components are presented along with detailed lists of supply vendors, components, and costs. Finally, safety measures incorporated in the final mechanical design and operation procedures for each of the subsystems are detailed.
\end{abstract}

\section{MVD Overview and Electronics Cooling Strategies}

The PHENIX experiment at the Relativistic Heavy Ion Collider (RHIC) at Brookhaven National Laboratory is being constructed to investigate a phase of matter termed the quark-gluon plasma. The plasma will be produced through the collision of two heavy ions. The multiplicity and vertex detector (MVD) located in the center of PHENIX will characterize the event, determine the collision point, and act as a central trigger. This report serves to present the detailed designs of the MVD's electronics cooling systems. Consequently, only relevant information of the most general and cooling system related components will be presented here. For a more thorough discussion, the reader is directed to the web site $h t t p: / / p 2 h p 2$. lanl.gov/phenix/mvd. 
The MVD, shown in Figure 1, is contained within an enclosure that opens in a "clam-shell" fashion to allow for installation around the ion-collision beam pipe. Each clam-shell-like half of the MVD is identical in construction and operation. The central portion of an MVD half section contains twelve C-shaped Rohacell foam cages that house silicon strip detectors used to detect charged particles emitted during heavy ion collisions. Each silicon cletector is connected with a Kapton cable to a multichip module (MCM) that contains the necessary electronics for reading, discriminating, and transmitting the detector signals. The MCMs are contained in a rectangular Rohacell plenum located beneath the $\mathrm{C}$-cages. Besides housing the $\mathrm{MCMs}$, the horizontal plenum also serves as a channel for cooling air. Located at either end of an MVD half section are aluminum end plates that house, in part, feedthroughs for the electronics, adapters for coolant lines, and MVD mounting connectors. Located within each end plate are a total of twelve silicon pad detectors and twelve corresponding MCMs to perform additional charged particle detection. Also located within each end plate is a motherboard that contains the electronics necessary to supply power and transmit information to all of the MCMs. Mounted on each motherboard are thirty-five low dropout voltage regulators (LDOs) that control the voltage to various MCM analog and digital components.

The electronics in the MCMs and LDOs generate a relatively large amount of heat that must be removed from the MVD to provide reliable operating temperatures. In addition, the temperature within the MVD enclosure must be controlled properly to maximize and maintain the signal-to-noise ratios of the silicon strip detectors. In addition, because Rohacell is a hygroscopic material, the humidity level within the enclosure must be controlled to ensure proper positioning and alignment of the Rohacell 


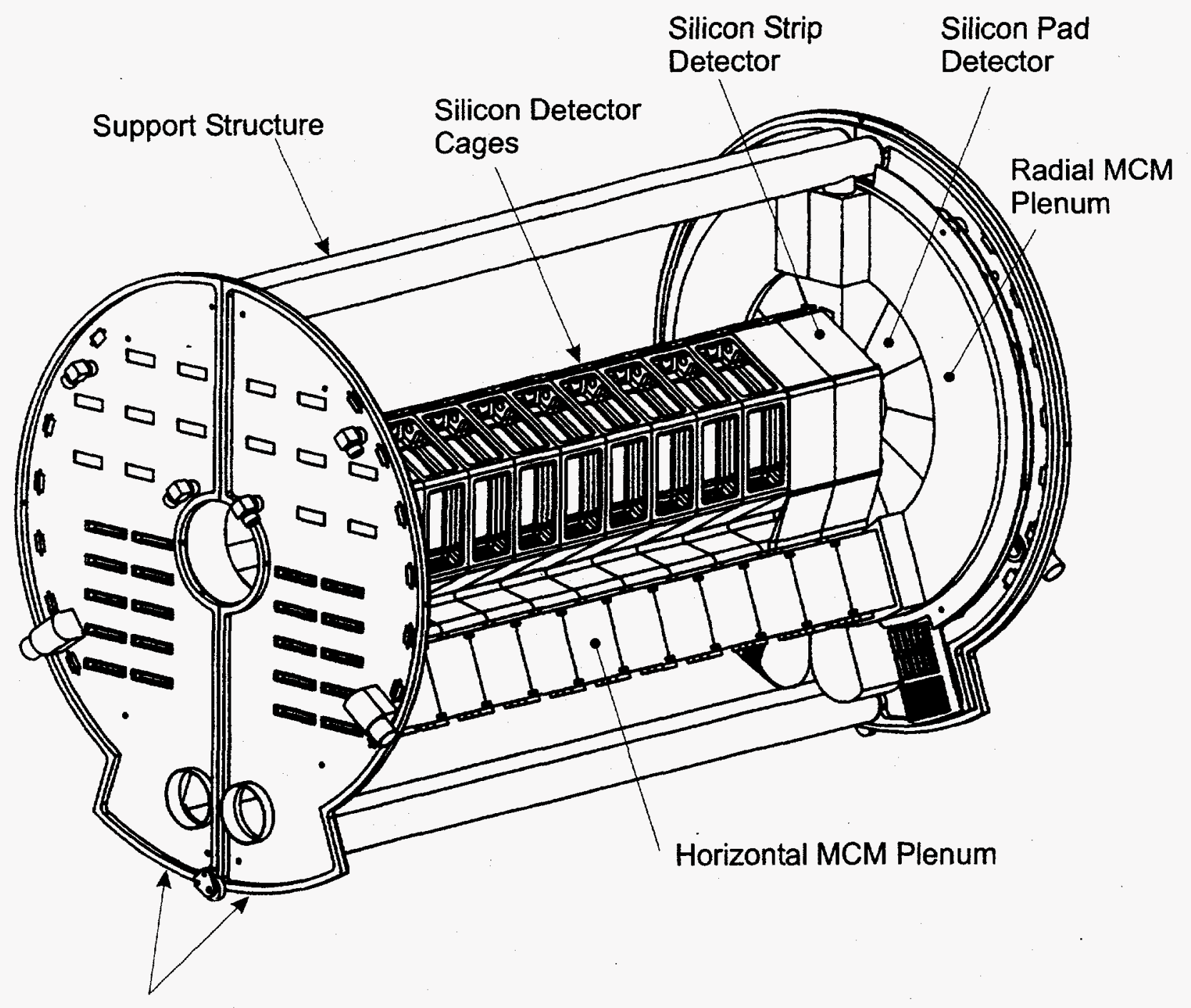

End Plates

Figure 1. Schematic diagram of the MVD showing the full set of silicon detector cage assemblies, horizontal MCM plenum, support structure, and end plates including motherboards, pad detectors, and radial MCM plenums. 
C-cages and silicon detectors. Consequently, three different environmental control systems have been proposed and analyzed both experimentally and numerically $[1,2,3$, 4]. Forced convection air systems were selected for cooling the MCMs (primary air cooling system) and controlling the enclosure environment (secondary air cooling system), but a forced convection liquid system was chosen for the LDO cooling strategy. The general layout of these three cooling systems is shown in Figure 2.

This report presents the detailed designs of the three environmental control systems as they currently stand. Each system is outlined in detail, including the desired operating characteristics as identified by earlier conceptual and prototype testing, general system layout and perforrnance descriptions, a list of components, vendors, and costs, and finally, a summary of the incorporated safety features. 


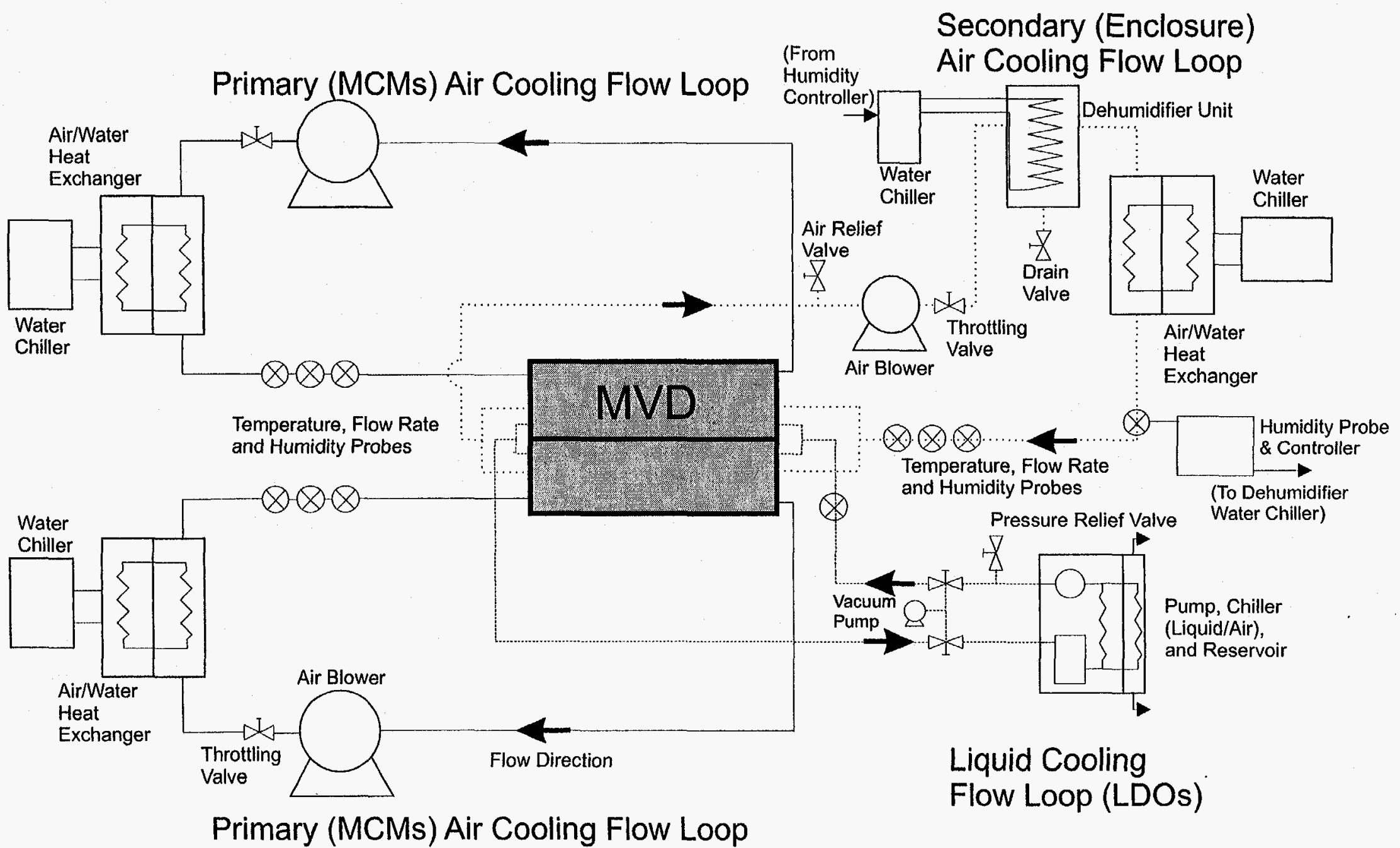

Figure 2. Schematic diagram of the MVD's three different cooling systems. 


\section{Design Procedure}

The complete engineering design procedure for the MVD's cooling systems was comprised of the following three steps:

1. Identify feasible cooling strategies that fit within the general design requirements of the MVD.

2. Design prototype cooling system configurations based on the proposed cooling strategies. Experimentally and/or numerically determine the operating performance and limitations of the proposed cooling systems based on specific requirements of the MVD's electronics.

3. Develop detailed designs of the actual MVD cooling systems that satisfy the MVD's thermal performance sriteria and the operational and physical constraints set forth by PHENIX management.

\section{Corrections for Altitude}

Los Alamos National Laboratory (LANL), where all of the MVD cooling system prototype tests were conducted, is located at an altitude of approximately 7,200 feet above sea level. Brookhaven National Laboratory (BNL), where the actual MVD will be installed and operated, is located at nearly sea level. This altitude difference between the two laboratories results in a significant difference in air pressure and density at the two locations. Consequently, caution must be exercised when using various experimental results from the MVD cooling system prototype tests in designing the final cooling systems. This section identifies the key variables that are influenced by air pressure and 
density and gives the relationships necessary to determine their values at either laboratory given the value at the opposite location.

\section{Heat Transfer Coefficient}

For the atmospheric pressure range encompassed by the LANL and BNL elevations, the heat transfer coefficient for turbulent internal flow is proportional to air density by the following $[5]$ :

$$
h \propto(\rho)^{0.8} .
$$

Using Equation (1), the ideal gas law, and atmospheric pressures of 14.5 psia and 11.5 psia for BNL and LANL, respectively, the following relationship can be derived for turbulent internal flow heat transfer coefficients at each location (assuming all conditions and properties are equal):

$$
h_{B N L}=1.22 h_{L A N L} \text {. }
$$

\section{Specific Humidity}

The specific humidity is also highly dependent on air density. For a given volume of air, $V$, the mass of water, $m$, present, is given by

$$
m=\rho \gamma V
$$


where $\rho$ is the air density and $\gamma$ is the specific humidity.

For equal amounts of water mass present in identical volumes of air at LANL and BNL, Equation (3) leads to the following relationship between the specific humidities at each location:

$$
\gamma_{B N L}=0.78 \gamma_{L A N L}
$$

\section{Volumetric Airflow Rate}

Volumetric airflow rate is commonly measured and expressed by fan and air blower manufacturers in their performance curves as standard cubic feet per minute (scfm), or airflow rate at standard sea level air pressure. Fans and blowers are constant volume devices, meaning that the volume of air they displace will remain constant with changes in air density. However, the mass of air that they displace will decrease with decreasing air density (or increasing altitude). Consequently, all volumetric airflow rates measured and reported fo: the MVD air cooling system prototype tests $[1,2,4]$ at LANL must first be converted to standard volumetric flow rates before performing air blower sizing calculations. Reviews on this conversion can be found in the literature $[6,7]$.

Lindeburg [6] showed how the corresponding standard volumetric airflow rate, $Q_{s c t m}$, can be obtained from the actual volumetric airflow rate, $Q_{a c t}$, measured at some pressure, $p_{a c t}$, other than that corresponding to sea level, $p_{a t m}$,

$$
Q_{s c / m}=\left(p_{a c t /} p_{a t m}\right) Q_{a c t}
$$


Assuming that atmospheric pressures at BNL and LANL are 14.5 psia and 11.5 psia, respectively, and that air volumetric flow rates at BNL correspond to standard conditions, then Equation (5) gives the relationship between air volumetric flow rates at BNL and LANL, or

$$
Q_{B N L}=Q_{s c f m}=(0.78) Q_{L A N L}
$$

Thus air volumetric flow rates measured at LANL, $Q_{L A N L}$, must be reduced by $78 \%$ to give the standard air volumetric flow rate needed for the air blower sizing charts provided by typical fan and blower manufacturers. 


\section{Cooling System Designs}

The following three sections describe the cooling system designs for the multichip modules, the MVD enclosire, and the low voltage drop regulators.

\subsection{Primary Air Cooling System for Multichip Modules}

The primary air cooling system will not be humidity controlled and will serve to cool the MCMs by bloving cool air through the horizontal and radial plenums. A complete description of experimental testing of the primary air cooling system for the MVD's MCMs can be found in [1] and thus only a summary of the performance characteristics will be presented here.

Before the experirnents, the design criteria for the MCM electronics were defined as follows:

- Maximum allowable MCM operating temperature $50^{\circ} \mathrm{C}$

- Cooling system design goal for maximum MCM operating temperature $40^{\circ} \mathrm{C}$

- Approximate power dissipation of single MCM $3.8 \mathrm{~W}$

- Cooling air supply temperature $10^{\circ} \mathrm{C}$ to $20^{\circ} \mathrm{C}$

- Dimensions of MCM $50 \mathrm{~mm}(\mathrm{H})$ by $48 \mathrm{~mm}(\mathrm{~L})$ by $1.7 \mathrm{~mm}(\mathrm{~T})$

- Equal and uniform heat dissipation from each side of all MCMs

As described in [1.], a full-scale mockup of the MVD was used with the design specifications listed above to assess the operating performance of the air cooling system. 
In particular, $\mathrm{MCM}$ operating temperatures were measured for various $\mathrm{MCM}$ power settings, coolant air supply temperatures, and coolant air volumetric flow rates. Table 1 summarizes the minimum coolant airflow rate required to maintain the worst-cooled $\mathrm{MCM}$ at the operating temperature design goal limit of $40^{\circ} \mathrm{C}$ for various $\mathrm{MCM}$ power settings and coolant air supply temperatures.

Table 1. Summary of minimum MVD inlet air volumetric flow rates required to maintain the last radial MCM (worst-cooled MCM) at an operating temperature of $40^{\circ} \mathrm{C}$ for various $\mathrm{MCM}$ heat dissipation rates and inlet air temperatures.

\begin{tabular}{|c|c|c|c|}
\hline $\begin{array}{c}\text { Individual MCM } \\
\text { Heat Dissipation } \\
\text { Rate (W) }\end{array}$ & $\begin{array}{c}\text { MVD Inlet Air } \\
\text { Temperature }\left({ }^{\circ} \mathrm{C}\right)\end{array}$ & $\begin{array}{c}\text { Minimum Required } \\
\text { MVD Inlet Air } \\
\text { Volumetric } \\
\text { Flow Rate at LANL } \\
\left(\mathrm{m}^{3} / \mathrm{s}\right)\end{array}$ & $\begin{array}{c}\text { Corresponding } \\
\text { Minimum Required } \\
\text { MVD Inlet Air } \\
\text { Volumetric } \\
\text { Flow Rate at BNL } \\
\left(\text { std m } \mathrm{m}^{3} \mathrm{~s}\right)\end{array}$ \\
\hline \hline 2 & 10 & 0.013 & 0.010 \\
\hline 2 & 20 & 0.020 & 0.015 \\
\hline 3 & 10 & 0.021 & 0.016 \\
\hline 3 & 20 & 0.026 & 0.020 \\
\hline 4 & 10 & 0.026 & 0.020 \\
\hline 4 & 20 & 0.035 & 0.027 \\
\hline
\end{tabular}

\subsubsection{System Description and Design Specifications}

The final design of the primary air cooling system for the MCMs is shown schematically in Figure 3. Because of the large MCM heat loads, large air plenum pressure drops, and the need for a large operating safety margin, separate airflow loops were chosen for each half of the MVD. Each air cooling loop consists of an air blower, air/water heat exchanger, water chiller, insulated tubing, and monitoring probes for temperature, airflow rate, and humidity. 


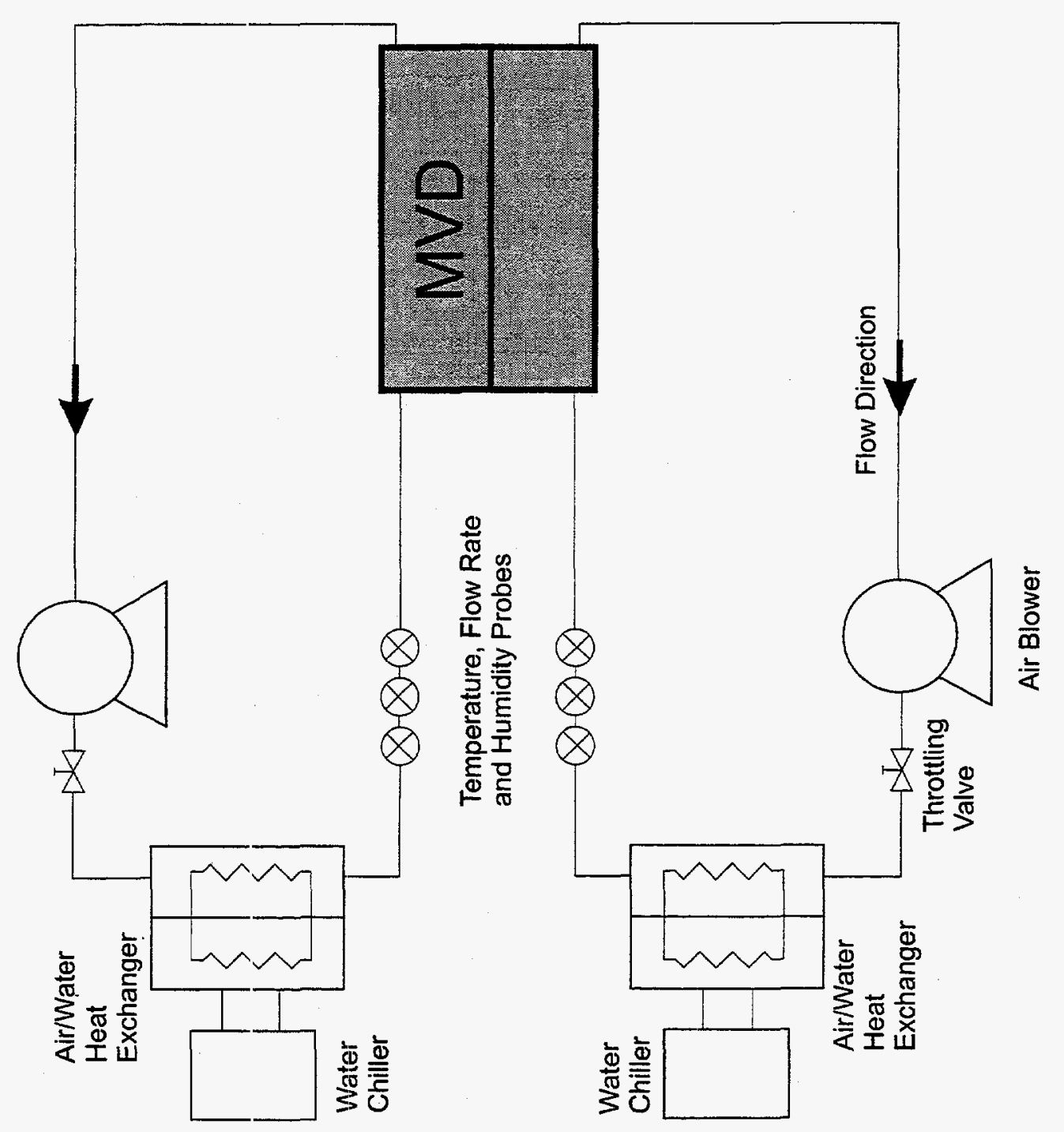

递 
As mentioned above, the experimental data used to size the various cooling system components were taken at LANL. However, the final design must be sized appropriately to operate at BNL. Consequently, all volumetric airflow rates measured at LANL will be converted to standard atmospheric volumetric flow rates (corresponding to BNL) before performing the design calculations.

\section{Sizing of Air Blower}

A maximum airflow rate of $0.035 \mathrm{~m}^{3} / \mathrm{s}(74 \mathrm{cfm})$ required by the primary air cooling system at LANL was reported in [1] and displayed above in Table 1. Using Equation (6), this flow rate in standard atmospheric conditions (corresponding to BNL) is 0.027 standard $\mathrm{m}^{3} / \mathrm{s}(58 \mathrm{scfm})$. In [1], this airflow rate was supplied by two Ametek blowers (model 11664201) operating in parallel. An Ametek fan performance curve shown in Figure 4 in standard atmospheric units, indicates that each fan, supplying a volumetric airflow rate of 0.0135 standard $\mathrm{m}^{3} / \mathrm{s}(29 \mathrm{scfm})$, could overcome a maximum operating pressure drop of $9.5 \mathrm{KPa}$ (38 in water). In a closed-loop, weakly compressible flow system such as this, the pressure drop, $\Delta P$, is equal to the square of the volumetric flow rate, $Q$, multiplied by the flow resistance of the loop, $R$, or

$$
\Delta P=Q^{2} R
$$

From Equation (7), it is apparent that to obtain with one blower, the flow rate of two single blowers operating in parallel, the same pressure drop must be overcome if the flow resistance is relatively constant over the range of flow rates. Thus, in order to 


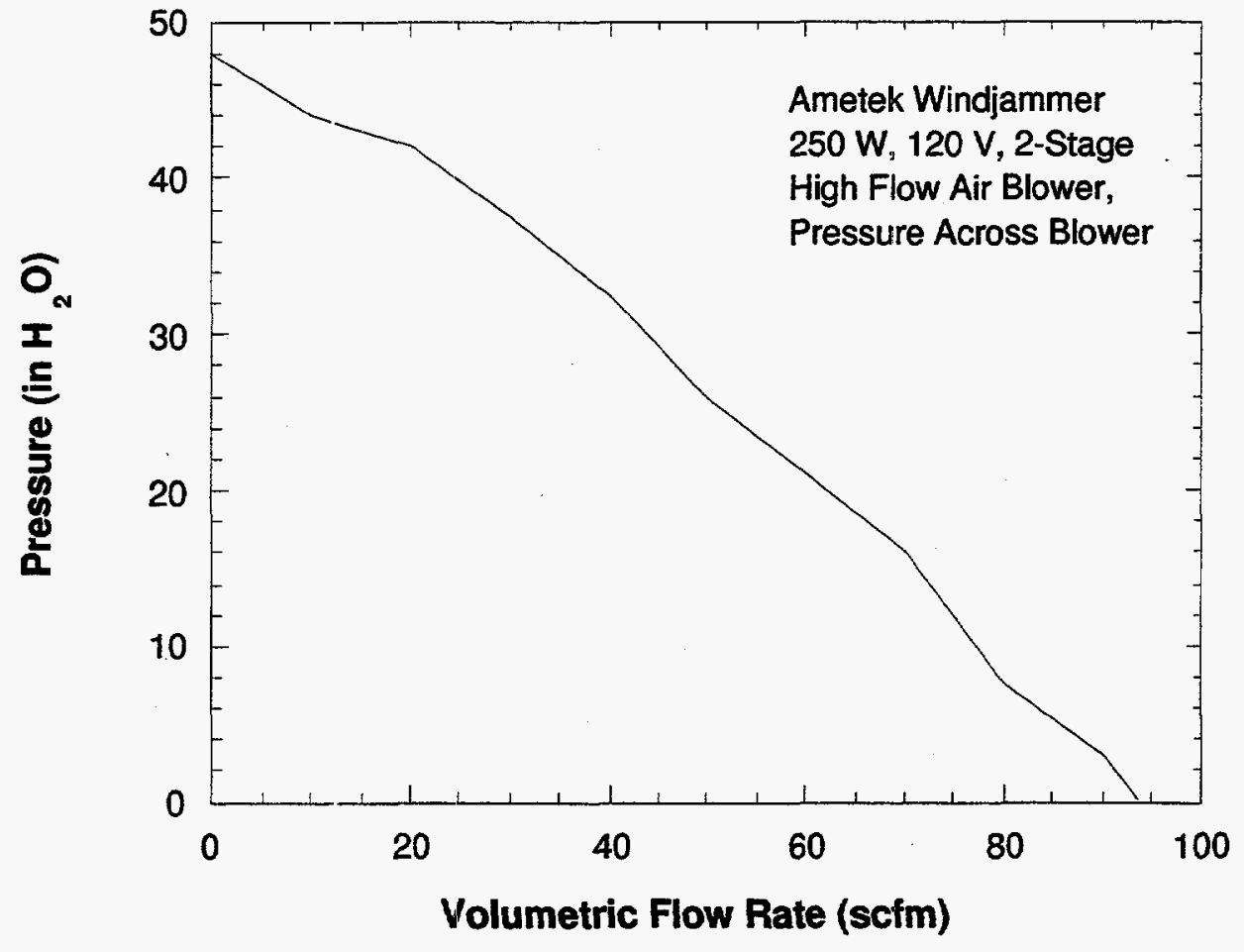

Figure 4. Performance curve for the Ametek Windjammer $250 \mathrm{~W}, 120 \mathrm{~V}$, two-stage, high flow rate blower. 
replace the two fans used in the prototype with a single unit in the final mechanical design, the single blower would need to supply an airflow rate of 0.027 standard $\mathrm{m}^{3} / \mathrm{s}$ (58 scfm) with a maximum pressure drop of $9.5 \mathrm{KPa}$ ( 38 in water).

\section{Sizing of Water Chiller and Heat Exchanger}

The water chiller must remove waste heat from an air-to-water heat exchanger and expel it to the environment. In addition, the heat exchanger must have an air side pressure drop of less than $6,986 \mathrm{~Pa}(1 \mathrm{psi})$ at an airflow rate of 0.027 standard $\mathrm{m}^{3} / \mathrm{s}(58$ scfm) to be consistent with that used in the prototype design of [1] and that used to size the air blower. The water side pressure drop of the heat exchangers must also be consistent with the capability of the water chiller's pump.

The maximum cooling capacity of the primary air cooling system was found in [1] and corresponds to the data in Table 1 for an MVD air inlet temperature of $10^{\circ} \mathrm{C}$ and an airflow rate of $0.020 \mathrm{standard} \mathrm{m}^{3} / \mathrm{s}(43 \mathrm{scfm})$. The total primary system heat load for one half of the MVD under these conditions can be broken down as follows:

- Heat load of MCMs $=68 \mathrm{MCMs}$ at $4 \mathrm{~W} / \mathrm{MCM}$ : $272 \mathrm{~W}$

- Heat load of air blower (approximated): $60 \mathrm{~W}$

- Heat load of MVD adapters and channels (found experimentally): $200 \mathrm{~W}$

- Heat load of tubing (approximated): $-60 \mathrm{~W}$ 
Using this heat load and the following operating conditions (extracted from experimental data of [1]), the heat exchangers and water chiller could be sized as follows:

- Airflow rate: 0.020 standard $\mathrm{m}^{3} / \mathrm{s}(43 \mathrm{scfm})$

- Air temperature at heat exchanger inlet: $28^{\circ} \mathrm{C}$

- Air temperature at heat exchanger outlet: $8^{\circ} \mathrm{C}$

- Water temperature at inlet of heat exchanger: $-2^{\circ} \mathrm{C}$

- Water flow rate: $0.63 * 10^{-4} \mathrm{~m}^{3} / \mathrm{s}(1 \mathrm{gpm})$

\section{Summary of Design Calculations}

Table 2 displays the design selection criteria for the individual primary air cooling system components. These criteria were based upon the experimental cooling system performance data shown earlier in Table 1, the design calculations of the previous section, as well as PHE]NIX operating and safety requirements. In addition to these selection criteria, there were general requirements of electrical compatibility (single phase 120 or $240 \mathrm{~V}$ at $60 \mathrm{~Hz}$ ) with the PHENIX facility, size compatibility with storage space in the PHENIX outriggers, and reasonable costs. 
Table 2. Design selection criteria for the primary air cooling system components.

\begin{tabular}{|c|c|}
\hline Component & Selection Criteria \\
\hline Air blower & 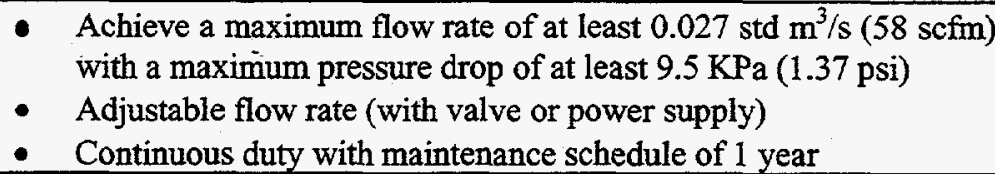 \\
\hline Water chiller & $\begin{array}{l}\text { - Heat removal rate of at least } 600 \mathrm{~W} \text { at a coolant delivery } \\
\text { temperature of } 0^{\circ} \mathrm{C} \text {. } \\
\text { - Coolant delivery temperature capability of }-10^{\circ} \mathrm{C} \text { with a stability } \\
\text { of } \pm 0.3^{\circ} \mathrm{C} \text {. } \\
\text { - Sealed reservoir } \\
\text { - Pump flow rate capability of at least } 0.63^{*} 10^{-4} \mathrm{~m}^{3} / \mathrm{s}(1 \mathrm{gpm}) \text { with } \\
\text { a pressure drop of } 84 \mathrm{KPa}(12 \mathrm{psi}) \\
\text { - Printinuous duty with maintenance schedule of } 1 \text { year } \\
\text { Pressure relief valve }\end{array}$ \\
\hline Air/water heat exchanger & $\begin{array}{l}\text { Heat removal rate of } 525 \mathrm{~W} \text { with the following boundary } \\
\text { conditions: Air inlet temp. }=28^{\circ} \mathrm{C} \text {, air outlet temp. }=8^{\circ} \mathrm{C} \text {, airflow } \\
\text { rate }=0.020 \text { standard } \mathrm{m}^{3} / \mathrm{s}\left(43 \mathrm{scfm} \text {, water inlet temp. }=2^{\circ} \mathrm{C} \text {, }\right. \\
\text { water flow rate }=0.63^{*} 10^{-4} \mathrm{~m}^{3} / \mathrm{s}(1 \mathrm{gpm})\end{array}$ \\
\hline Tubing and insulation & $\begin{array}{l}\text { - Flexible sections for routing lines } \\
\text { - } \quad \text { Insulated to ms for connecting monitoring proat gains and prevent condensation } \\
\text { - Conforms with BNL fire safety codes }\end{array}$ \\
\hline $\begin{array}{l}\text { Monitoring probes } \\
\text { (temperature, airflow rate, } \\
\text { and humidity) }\end{array}$ & $\begin{array}{l}\text { Voltage output of } 1 \text { to } 5 \mathrm{~V} \text { over the corresponding parametric } \\
\text { range: Temperature: } 0^{\circ} \mathrm{C} \text { to } 50^{\circ} \mathrm{C} \text {, relative humidity: } 5 \% \text { to } \\
95 \% \text {, air volumetric flow rate: } 0 \text { to } 0.040 \text { standard } \mathrm{m}^{3} / \mathrm{s}(85 \mathrm{scfm} \text { ). }\end{array}$ \\
\hline
\end{tabular}

\subsubsection{Components and Costs List}

The cooling system component selections, summarized in Table 3, were based on the design criteria presented previously. A short discussion is provided below concerning the selection of the major components, including the air blower, water chiller, and heat exchanger. 
Table 3. Itemized list of components for the primary air cooling system (this does not include prices for spare parts or backup components).

\begin{tabular}{|c|c|c|c|c|}
\hline Item & $\begin{array}{l}\text { Supplier, Catalog No., } \\
\text { Comments }\end{array}$ & $\begin{array}{l}\text { Unit Cost } \\
\text { (No tax or } \\
\text { shipping) }\end{array}$ & Quantity & $\begin{array}{c}\text { Total Cost } \\
(\$) \\
\end{array}$ \\
\hline $\begin{array}{l}\text { Air blower } \\
\text { (including } 2 \mathrm{hp} \text { motor, } \\
4 \text { " to } 3 \text { " reducer and } \\
\text { coupler, 3" to } 2 " \\
\text { reducer and coupler) }\end{array}$ & $\begin{array}{l}\text { Sonic Air, SAS-700, } \\
\text { Motor }=2 \mathrm{hp}, \\
\text { Mean time between failures } \\
=10 \text { to } 12 \mathrm{~K} \mathrm{~h}, \\
\text { Bearing life }=14 \mathrm{~K} \mathrm{~h}, \\
\text { Drive belt }=6 \mathrm{~K} \mathrm{~h} \text {, Motor } \\
\text { life }=5 \text { to } 7 \mathrm{y}\end{array}$ & 2,782 & 2 & 5,564 \\
\hline Water chiller & $\begin{array}{l}\text { FTis Systems, RS44LT, } \\
\text { Positive displacement pump } \\
\text { with water flow }=1.6 \mathrm{gpm} \\
\text { at } 100 \mathrm{psi} \\
\text { Cooling capacity }=670 \mathrm{~W} \text { at } \\
0^{\circ} \mathrm{C} \text {, }\end{array}$ & 3,180 & 2 & 6,360 \\
\hline Heat exchanger & $\begin{array}{l}\text { Lytron, } 6110, \\
\text { Lytron to supply heat } \\
\text { exchanger cores. A machine } \\
\text { shop vendor is required to } \\
\text { fabricate heat exchanger } \\
\text { casing. }\end{array}$ & & & \\
\hline Air velocity meter & $\begin{array}{l}\text { Oriega, FMA-905-V, } \\
\text { Range }=10 \text { to } 5000 \mathrm{SFPM}, \\
\text { Input }=15 \text { to } 24 \mathrm{Vdc}, \\
\text { Output }=0 \text { to } 5 \mathrm{Vdc} \text {. }\end{array}$ & 822 & 1 & 822 \\
\hline $\begin{array}{l}\text { Humidity and } \\
\text { temperature sensor, }\end{array}$ & $\begin{array}{l}\text { Orega, HX } 11 \mathrm{~V}, \\
\text { Range }=0^{\circ} \mathrm{C} \text { to } 100^{\circ} \mathrm{C}, 5 \% \\
\text { to } 55 \% \mathrm{RH}, \\
\text { Input }=12 \text { to } 36 \mathrm{Vdc}, \\
\text { Oufput }=1 \text { to } 5 \mathrm{Vdc} \text {, }\end{array}$ & 205 & 2 & 410 \\
\hline Tubing and fittings & $\begin{array}{l}\text { Accurate Plastics, } \\
\text { Altuquerque Valve and } \\
\text { Fitting, Co., }\end{array}$ & & & \\
\hline Insulation & Grainger & & & \\
\hline Total & 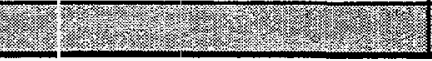 & & & $(13,156)$ \\
\hline
\end{tabular}

\section{Air Blower}

The Sonic SAS-700 blower was chosen because of its high performance, long lifetime over continuous operation, and relatively low cost. The brake horsepower and discharge pressure curves versus airflow rate for various rpms are shown in Figure 5. To provide a flow rate of $0.027 \mathrm{~m}^{3} / \mathrm{s}(58 \mathrm{scfm})$ while handling a pressure drop of $9.5 \mathrm{KPa}$ 
H.P. vs. C.F.M

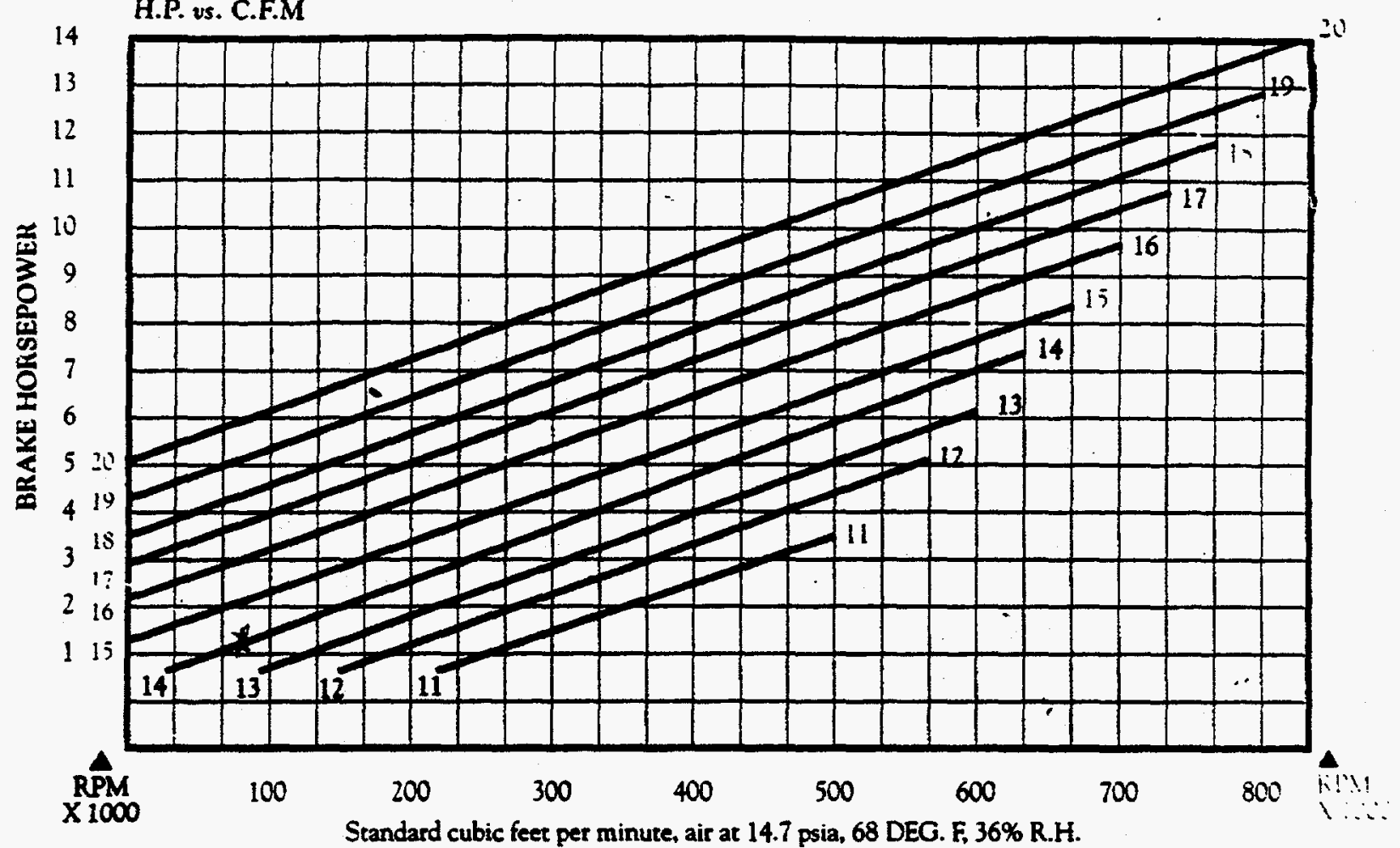

Z

Pressure us. C.F.M

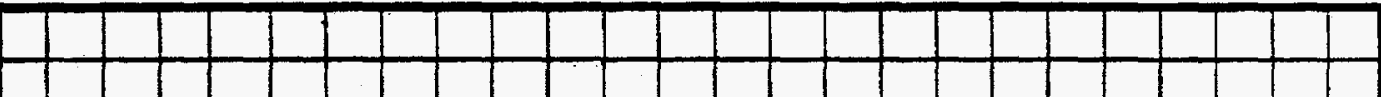

110

100

90

80

70

6017

50

$\stackrel{x}{x}$

14

3013

20

10

$$
\text { (1) }
$$

Rrit

$x+i 20$

100

$200 \quad 300$
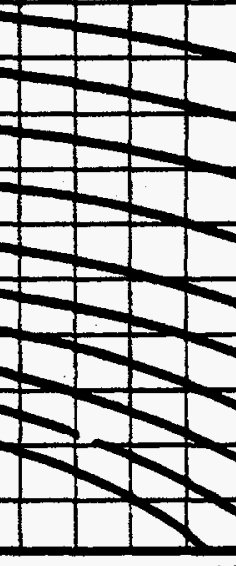

$+\infty$

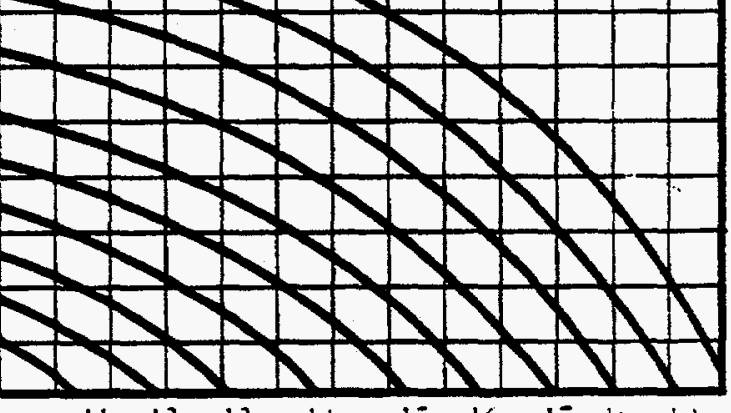

$\begin{array}{lllllllll}11 & 12 & 13 & 1: & 15 & 16 & 17 & 1 & 1.1 \\ 500 & & 000 & & 700 & & 800\end{array}$

Standard cubic feet per minute, air at 14.7 psia, 68 DEG. F, 36\% R.H.

l" $\mathrm{H}_{2} \mathrm{O}=.074^{\prime \prime} \mathrm{Hg}=.036 \mathrm{PSIG}=.57 \mathrm{oz}=25.4 \mathrm{~mm} \mathrm{H}, \mathrm{O}$

Figure 5. Performance curves for the Sonic SAS-700 Air Blower. 
(38 in water), a $2 \mathrm{hp}$ (or \&reater) motor is required to provide a sufficient safety cushion. Other beneficial features :nclude the small size of the unit $\left(56 * 30 * 57 \mathrm{~cm}^{3}\right)$ that allows it to fit within the PHENIX outrigger supports, the availability of inlet and outlet adapters to fit $50.8 \mathrm{~mm}$ ( 2 in.) tubing, a belt drive to eliminate heat dumping from the motor to the airflow, and long component lifetimes (see Table 2).

\section{Water Chiller}

Two FTS System: RS44LT water chillers with the positive displacement pump option were selected to remove the waste heat from the primary air cooling systems in each clamshell half of the MVD ( $600 \mathrm{~W} /$ half, $1200 \mathrm{~W}$ total). A single RS44LT has a heat rate removal capacity of $760 \mathrm{~W}$ at a $0^{\circ} \mathrm{C}$ coolant temperature, and a minimum coolant supply temperature of $-40^{\circ} \mathrm{C}$ with a temperature stability of $\pm 0.1^{\circ} \mathrm{C}$. The sealed reservoir holds 4 liters of coolant and the optional positive displacement pump will deliver a coolant flow rate of $1.01^{: k} 10^{-4} \mathrm{~m}^{3} / \mathrm{s}(1.6 \mathrm{gpm})$ at a pressure drop of $698 \mathrm{KPa}(100 \mathrm{psi})$. The overall dimensions $\left(33 * 53.3 * 48.3 \mathrm{~cm}^{3}\right)$ are small enough that the chillers can be placed in the openings in the PHENIX outrigger supports. Finally, the waste heat from the chiller is removed by a fan to the environmental air. However, air conditioning systems in the PHENIX Major Facility Hall will effectively transfer this waste heat to the outer environment. The R.S44LT requires a 208 to $230 \mathrm{~V}$ input at $60 \mathrm{~Hz}$ and draws $7 \mathrm{~A}$.

\section{Heat Exchanger}

The air-to-water heat exchangers, shown schematically in Figure 6, will be designed much like the prototype used in the experimental cooling tests $[1,2,4]$. Two 


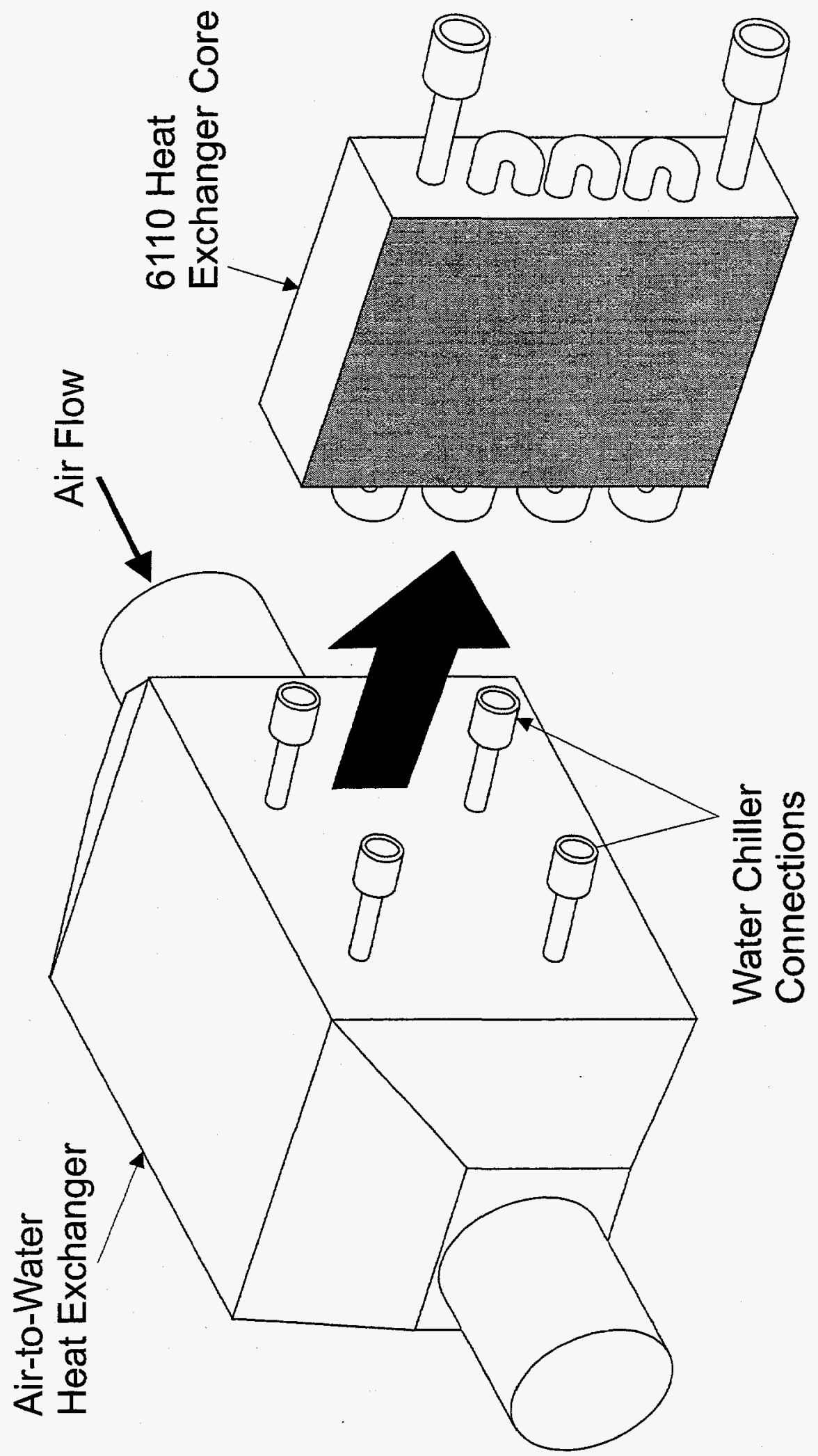

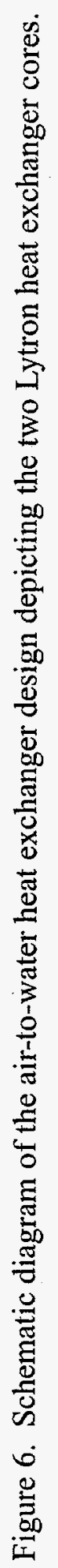


copper tube and fin heat exchanger cores (model 6110) provided by Lytron, Inc., will be encased within an insulated shell enclosure through which the coolant airflows. Coolant water, supplied by the RS44LT water chiller, will pass through the tubes of each core and remove heat through extended fins from the airflow stream. The thermal performance, air side pressure drop, and water side pressure drop curves for a single 6110 heat exchanger core are shown in Figures 7(a) through 7(c). Using the operating criteria presented earlier for the heat exchanger $\left(43 \mathrm{scfm}\right.$ airflow rate, $28^{\circ} \mathrm{C}$ air inlet temperature, $8^{\circ} \mathrm{C}$ air outlet temperature, $1{ }^{\circ} \mathrm{C}$ water outlet temperature, $1.6 \mathrm{gpm}$ water flow rate), and a heat exchanger sizing scheme provided by Lytron, the thermal performance curves of several different heat exchanger cores were investigated. A thermal performance of $22 \mathrm{~W} /{ }^{\circ} \mathrm{C}$ was needed to satisfy the cooling requirements for the primary air cooling system for one half of the MVD. A single 6110 heat exchanger core operating at an airflow rate of 43 scfm and a water flow rate of $1.6 \mathrm{gpm}$ has a thermal performance of $16 \mathrm{~W} /{ }^{\circ} \mathrm{C}$. Thus, a decision was made to use two 6110 heat exchanger cores operating in series which would easily deliver the required cooling performance. For one primary air cooling system, two 6110 heat exchanger cores operating in series at the specified flow rates would result in air and water side pressuse drops of $0.007 \mathrm{psi}$ and $10 \mathrm{psi}$, respectively. These pressure drops can be sufficiently handled by the air blower and water chiller pump.

\section{Instrumentation}

An HX11V proke from Omega was chosen to provide relative humidity (temperature compensated) and temperature measurements of the primary air cooling 
(a)

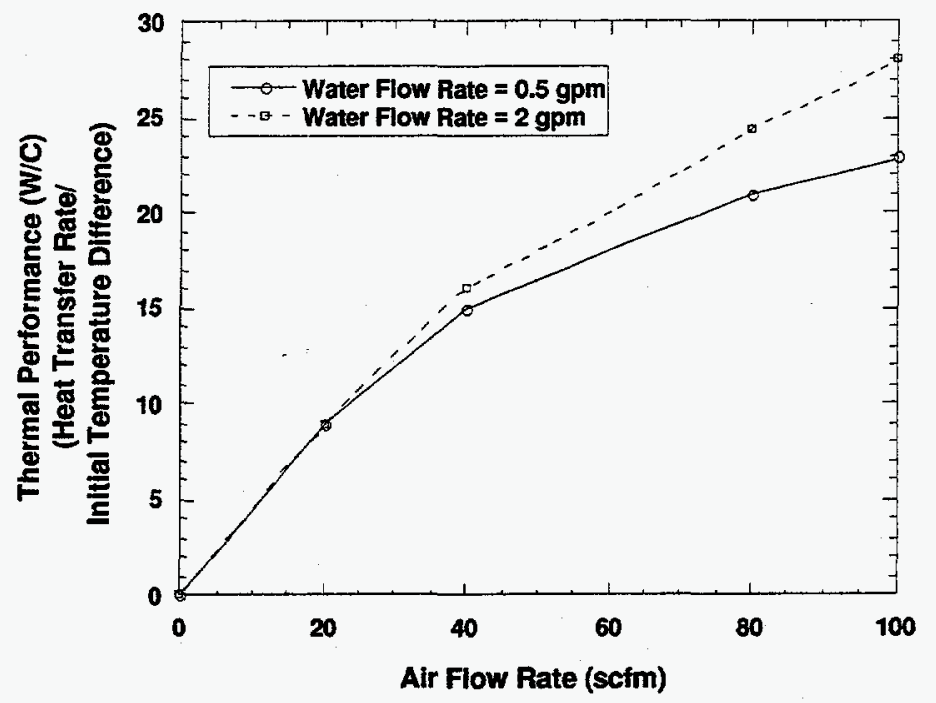

(b)

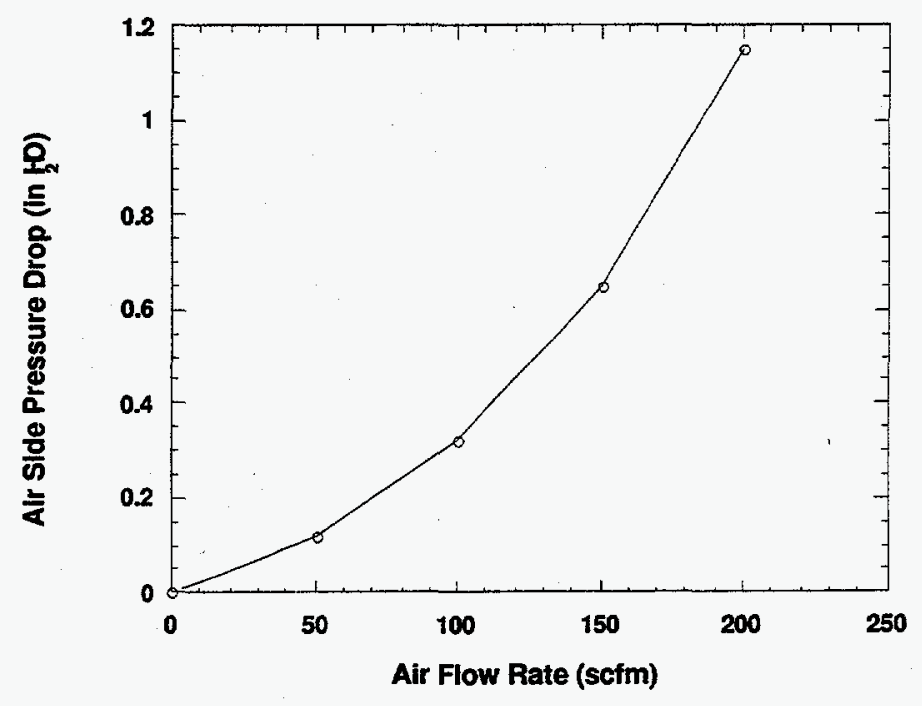

(c)

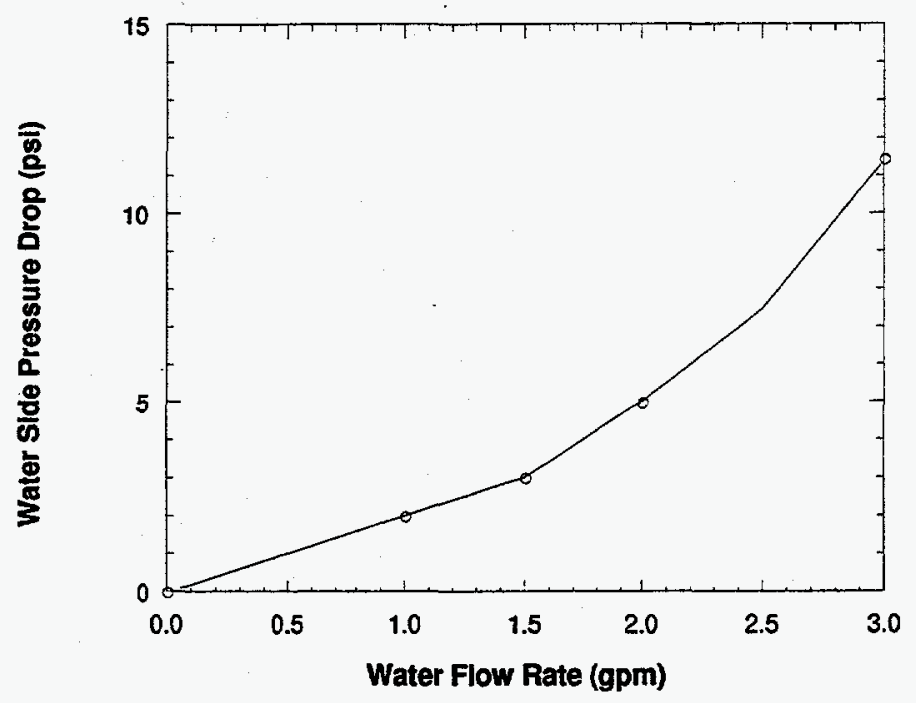

Figure 7. Performance curves for the Lytron 6110 air-to-water heat exchanger including (a) thermal performance, (b) air side pressure drop, and (c) liquid side pressure drop. 
system air exiting the air-to-water heat exchanger. This unit has relative humidity and temperature ranges of $5 \%$ to $95 \%( \pm 2 \%)$ and $0^{\circ} \mathrm{C}$ to $100^{\circ} \mathrm{C}\left( \pm 0.6^{\circ} \mathrm{C}\right)$, respectively. The probe gives a linear direct voltage output of 1 to $5 \mathrm{Vdc}$ for both relative humidity and temperature. The sensors are placed in a stainless steel (316SS) watertight sheath that has a $130 \mathrm{~mm}(5.1 \mathrm{in}$.) length and a $16 \mathrm{~mm}(0.625 \mathrm{in}$.) diameter. A compression fitting will be required to mount the sensor in the center of the airflow line downstream of the heat exchanger. The sensor will require a direct current input voltage in the range of 12 to 36 Vdc for operation.

An Omega (FMA-905-V) hot wire anemometer with a range of 10 to $5,000 \mathrm{sfpm}$ (standard $\mathrm{ft} / \mathrm{min})( \pm 1.5 \%)$ will be used to monitor the mean airflow velocity at the same location as the temperature/humidity measurements. The volumetric airflow rate can be determined by multiplying the mean airflow velocity by the cross-sectional area of the pipe at the instrument's lccation. The probe gives a linear direct voltage output of 0 to 5 Vdc for air velocity. The hot wire sensor is placed in a stainless steel (316SS) sheath that has a $330 \mathrm{~mm}$ (13 in.) length and a $6.35 \mathrm{~mm}$ (0.250 in.) diameter. A compression fitting will be required to mount the sensor in the center of the airflow line downstream of the heat exchanger. The sensor will require a direct current input voltage in the range of 15 to $24 \mathrm{Vdc}$ for operation.

\section{Tubing, Fittings, and Insulation}

Accurate Plastics Inc., and Albuquerque Valve and Fitting have been chosen as the suppliers of tubing and fittings. Accurate Plastics can provide both rigid and flexible tubing for the airflow lines, and Albuquerque Valve and Fitting can supply the 
compression fittings needed for installing the instrumentation. Grainger, a vendor for industrial equipment and supplies, has a large variety of insulation tapes and pipe sleeves. Fire code criteria for these insulation materials are specified by the vendor. Because the exact placement of components and routing of coolant lines has not yet been determined, the precise amount of tubing, fittings, and insulation cannot be determined at this point in time.

\subsubsection{Safety Measures}

Several safety measures have been included in the final primary air cooling system design to ensure proper operating performance of the MCMs. These measures are as follows:

- A design goal temperature limit of $40^{\circ} \mathrm{C}$ for the operating temperature of the MCMs was used to base the cooling requirements for the air cooling system. This design goal is conservatively $10^{\circ} \mathrm{C}$ below the operating temperature limit of $50^{\circ} \mathrm{C}$ for the MCMs.

- The experiments used to determine the heat loads on the primary air cooling system did not rely on the cooled environment of the MVD main enclosure in contact with the horizontal and radial MCM plenums that will exist in the final MVD. Consequently, an extra environmental heat load was imposed on the experimental primary air cooling system that will not exist in the final assembly. However, the design of the primary air cooling system was based on the experimental setup.

- The air density at BNL, where the final MVD assembly is to operate, is roughly $20 \%$ higher than that at LANL where the cooling experiments were conducted. 
Consequently, for a given air volumetric flow rate in the primary cooling system at both LANL and BNL, the heat transfer coefficient of the cooling air at BNL will be approximately $20 \%$ greater than that at LANL. This will result in lower MCM operating temperatures at BNL compared to those predicted at LANL by a few degrees centigrade [1].

- Oversized air blowers, chillers, and heat exchangers were selected for the final design to allow a cushion in the available cooling power supply should abnormal conditions arise.

\subsubsection{System Operation}

The setup and operation of the primary air cooling system will proceed as follows:

1. Both air blowers are turned on, and the flow rates in each flow loop are adjusted manually by opening or closing throttling valves, located just downstream of each blower, until the desired flow rate of $0.027 \mathrm{standard} \mathrm{m}^{3} / \mathrm{s}(55.5 \mathrm{scfm}$ ) (corresponds to a standard air velocity of 2,546 fpm in a 2 in. pipe) is obtained, as displayed by the air velocity probe.

2. The water chillers for each of the two air-to-water heat exchangers will be activated and adjusted manually until the desired MVD inlet air temperature of $10^{\circ} \mathrm{C}$ is achieved, as determined with the aid of the temperature probe and display.

3. Fine adjustment of the flow rate and chiller temperature will be required once the MVD electronics have been turned on and allowed to reach steady-state operation. 


\subsection{Secondary Air Cooling System for Enclosure}

The secondary air cooling system will serve to control the temperature and humidity of the air surrounding the silicon strip detectors by blowing cool and dehumidified air through the main enclosures. The temperature control is necessary to maximize the signal-to-noise ratio of the silicon strip detectors. The desired temperature range for operation of these detectors is $10^{\circ} \mathrm{C}$ to $20^{\circ} \mathrm{C}$. The humidity control is necessary to prevent the hygroscopic Rohacell cages from flexing with changes in humidity, which would reduce the location certainty of the silicon strip detectors and hence reduce the effectiveness of the detector in locating the origin of particle collisions. The loss in vertex-finding efficiency of the MVD has been estimated to be $5 \%$ and $10 \%$ for maximum excursions in relative humidity (at $23^{\circ} \mathrm{C}$ ) of $9 \%$ and $18 \%$, respectively [8]. This corresponds to specific humidity excursions of 0.0015 and $0.030 \mathrm{~kg} \mathrm{H} \mathrm{H}_{2} \mathrm{O} / \mathrm{kg}$ air. A complete description of experimental testing of a prototype air cooling system for the MVD enclosures can be found in [4] and thus only a summary of the performance characteristics will be presented here.

Before the experiments, the design criteria for the MVD's main enclosure that surrounds the silicon strip detectors, were defined as follows:

- Operating temperature range for enclosure $10^{\circ} \mathrm{C}$ to $20^{\circ} \mathrm{C}$

- Specific humidity operating range design goal (assuming a maximum $\pm 9 \%$ excursion in relative humidity from a mean value of $30 \%$ at $23^{\circ} \mathrm{C}$ or a $0.0015 \mathrm{~kg} \mathrm{H}_{2} \mathrm{O} / \mathrm{kg}$ Air excursion in specific humidity from a mean value 
of $0.0068 \mathrm{~kg} \mathrm{H}_{2} \mathrm{O} / \mathrm{kg}$ air at LANL conditions)

(LANL conditions) 0.0045 to $0.009 \mathrm{~kg} \mathrm{H}_{2} \mathrm{O} / \mathrm{kg}$ air

[corresponding BNL conditions using Eqn. (4)] ----0.0035 to $0.007 \mathrm{~kg} \mathrm{H} 2 \mathrm{O} / \mathrm{kg}$ air

As described in [4], a full-scale mockup of the MVD was used with the design specifications listed above to assess the operating performance of the air cooling system. In particular, the heat load and average temperature of the MVD's main enclosure were measured for various coolant air supply temperatures and volumetric flow rates. In addition, several differen: methods to reduce and control the humidity level within the enclosure were also tested and evaluated. The most promising technique to remove moisture from the circulating air relied on condensation of the water vapor onto the heat exchanger and dehumidifier surfaces.

Table 4 summarizes the cooling system parameter operating values necessary to meet the design requirements given above. These parameter values were established from the empirical data obtained with the enclosure cooling system prototype [4]. It should be noted that the heat removal rate of the dehumidifier unit was conservatively approximated. The Neslab Endocal RTE4 water chiller used to cool the dehumidifier was designed with a cooling capacity of $400 \mathrm{~W}$ at $0^{\circ} \mathrm{C}$. However, the chiller was 15 years old and it was estimated that this cooling capacity had been reduced by at least $25 \%$, as was evident by the chiller's limited ability to reach its lowest operating temperature of $0^{\circ} \mathrm{C}$ rather than its designed limit of $-30^{\circ} \mathrm{C}$. Consequently, it was estimated that the dehumidifier unit was removing at most $300 \mathrm{~W}$ from the airflow for one half of the MVD. Thus, the total heat removal for both MVD enclosures would be $600 \mathrm{~W}$ at $0^{\circ} \mathrm{C}$. 
Table 4. Summary of the cooling system parameter operating values required to meet the performance criteria of the secondary air cooling system for both enclosure halves of the MVD.

\begin{tabular}{|c|c|}
\hline Parameter & Operating Value \\
\hline $\begin{array}{c}\text { Air volumetric flow rate and } \\
\text { pressure drop }\end{array}$ & 0.023 standard $\mathrm{m}^{3} / \mathrm{s}(50 \mathrm{scfm})$ at $15.7 \mathrm{KPa}\left(59.1 \mathrm{in} \mathrm{H}_{2} \mathrm{O}\right)$ \\
\hline MVD air inlet temperature & $8^{\circ} \mathrm{C}$ \\
\hline $\begin{array}{c}\text { Heat removal rate of } \\
\text { heat exchanger and chiller }\end{array}$ & $450 \mathrm{~W}$ \\
\hline $\begin{array}{c}\text { Heat removal rate of } \\
\text { dehumidifier unit and chiller }\end{array}$ & $600 \mathrm{~W}$ \\
\hline $\begin{array}{c}\text { Condensation surface } \\
\text { requirements for keeping } \\
\text { within specific humidity } \\
\text { level operating range } \\
\text { (assuming condensation on } \\
\text { heat exchanger and } \\
\text { dehumidifier surfaces) }\end{array}$ & $\begin{array}{c}\text { Coolant supply temperature to dehumidifier: }-5^{\circ} \mathrm{C} \\
\text { Coolant supply temperature to heat exchanger: } 0^{\circ} \mathrm{C}\end{array}$ \\
\hline
\end{tabular}

\subsubsection{System Description and Design Specifications}

The final design of the secondary air cooling system for the MVD's main enclosures is shown schematically in Figure 8. Unlike the primary air cooling system that required separate flow loops for each half of the MVD, the secondary cooling system requires only a single flow loop for the entire MVD (two enclosures). The secondary system consists of an air blower and throttling valve for controlling the airflow rate, an air-to-water heat exchanger connected to a water chiller for controlling the air temperature, a dehumidifier unit with a water draining system for controlling the 


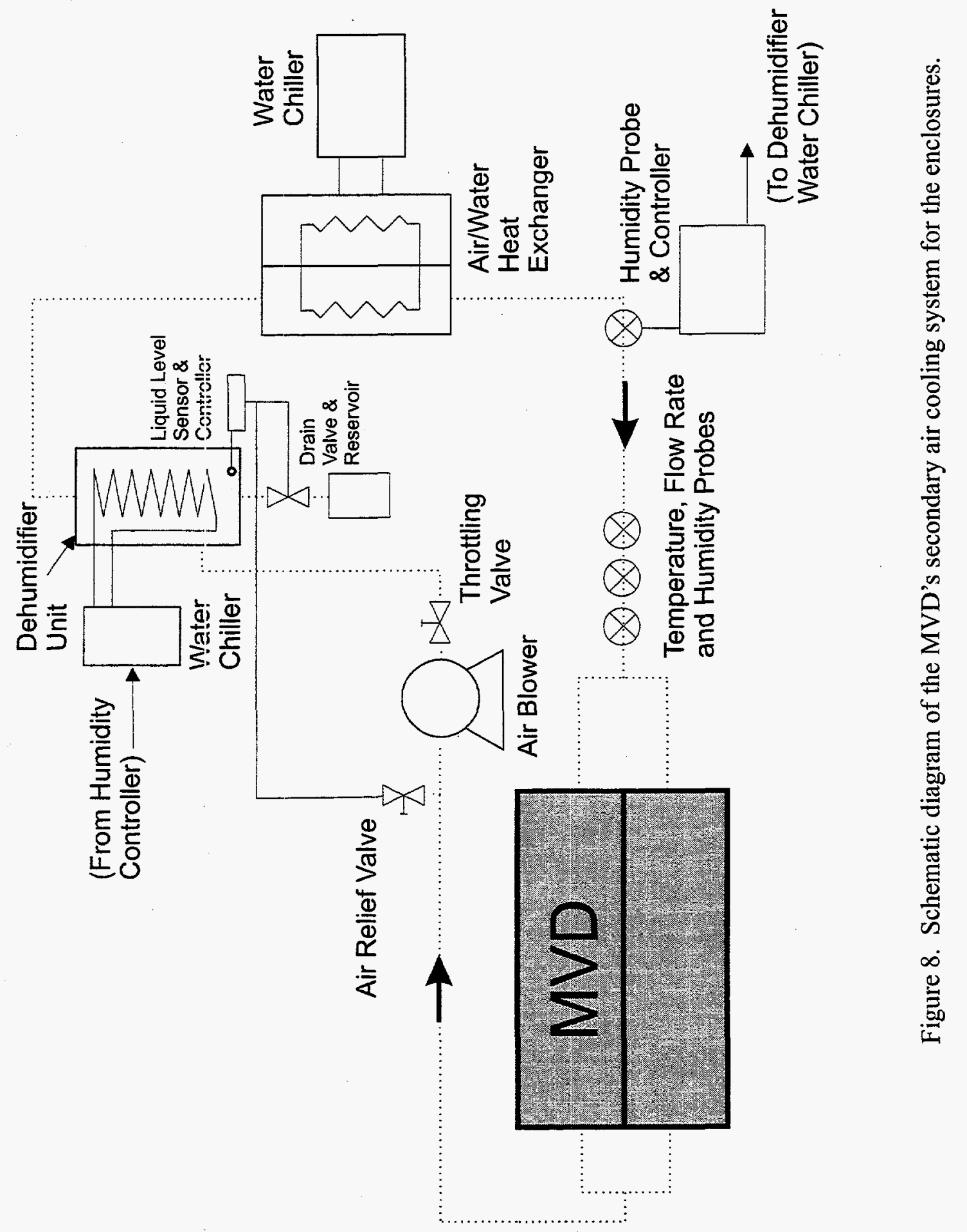


humidity, insulated tubing, and monitoring probes for temperature, airflow rate, and humidity.

\section{Sizing of Air Blower}

A minimum airflow rate of $0.030 \mathrm{~m}^{3} / \mathrm{s}(64 \mathrm{cfm})$ is required for both halves of the MVD enclosure, as determined previously in [4]. Using Equation (6), this flow rate in standard atmospheric conditions (corresponding to BNL) is 0.023 standard $\mathrm{m}^{3} / \mathrm{s}$ (50 scfm). In [4], an Ametek blower (model 11664201) was used to provide a standard air volumetric flow rate of 0.012 standard $\mathrm{m}^{3} / \mathrm{s}(25 \mathrm{scfm})$ for one half of the MVD. The operating performance curve for this blower, shown previously in Figure 4, indicates that at 0.012 standard $\mathrm{m}^{3} / \mathrm{s}(25 \mathrm{scfm})$, the corresponding pressure drop is $10,600 \mathrm{~Pa}$ (40 in water).

In sizing the air blower, the following three general rules were used to minimize pressure drops:

(1) The pressure drop through any structure is inversely proportional to the square of the cross-sectional area for a constant flow rate.

(2) The pressure drop through any element is approximately directly proportional to the airflow rate squared.

(3) The pressure drop through any structure is proportional to the length of the structure (except for short structures with a length less than five to ten equivalent diameters). 
The prototype cocling system of [4] used $50.8 \mathrm{~mm}(2 \mathrm{in}$.) diameter tubing and equivalent $50.8 \mathrm{~mm}$ diameter adapters connecting the cooling air supply tubing to the MVD. However, the current design calls for $19.1 \mathrm{~mm}(0.75 \mathrm{in}$.) diameter airflow adapters, which will provide a substantially higher pressure drop across the flow loop for the same flow rate. Consequently, this additional pressure drop must be determined to correctly size the air blower for the final design.

A flow rate of 0.012 standard $\mathrm{m}^{3} / \mathrm{s}(26 \mathrm{scfm})$ (through one half of the MVD) through a $19.1 \mathrm{~mm}(0.75 \mathrm{in}$.) diameter tube corresponds to a mean velocity of $41.9 \mathrm{~m} / \mathrm{s}$ (138 ft/s). Assuming that a $1 \mathrm{~m}(3.281 \mathrm{ft})$ of $19.1 \mathrm{~mm}(0.75 \mathrm{in}$.$) tubing is connected to a$ 90 degree elbow (as called for in the present design), which is connected to the MVD endplate, then the pressure drop through this section can be determined as follows. The major head loss, $h_{l m a j}$, thrcugh the pipe is given by [9] as

$$
h_{l m a i}=f^{\frac{l v^{2}}{d 2}}
$$

where $f$ is a friction factor (shown in graphical form in [9]), $l$ is the pipe length, $d$ is the pipe diameter, and $v$ is the average flow velocity.

The minor head loss, $h_{\text {lmin }}$, through the 90 degree elbow and orifice opening into the MVD's enclosure, is given by [9] 


$$
h_{l \min }=k \frac{v^{2}}{2}
$$

where $k$ is an empirical constant that has been tabulated for many different flow obstruction types and geometries.

The pressure drop caused by head loss is determined by multiplying the head losses from Equations (8) and (9) by the fluid density, $\rho$,

$$
\Delta P=\rho h_{l}
$$

Table 5 summarizes the head loss calculations [from Equations (8) and (9)] for three different pipe diameters for the MVD air inlet/outlet adapters at standard atmospheric conditions.

Table 5. Summary of head losses of the MVD secondary cooling system air inlet/outlet adapters for various pipe diameters and an air volumetric flow rate of 0.012 standard $\mathrm{m}^{3} / \mathrm{s}(25 \mathrm{scfm}$ ) (corresponding to one half of the MVD).

\begin{tabular}{|c|c|c|c|c|c|c|c|c|}
\hline$d(\mathrm{~mm})$ & $v(\mathrm{~m} / \mathrm{s})$ & $\begin{array}{c}F \\
{[9]}\end{array}$ & $\begin{array}{c}k_{\text {elbow }} \\
{[9]}\end{array}$ & $\begin{array}{c}k_{\text {orifice }} \\
{[9]}\end{array}$ & $\begin{array}{c}h_{\text {lmaj }} \\
(\mathrm{m} / \mathrm{s})^{2}\end{array}$ & $\begin{array}{c}h_{\text {imin }}, \\
(\mathrm{elbow}) \\
(\mathrm{m} / \mathrm{s})^{2}\end{array}$ & $\begin{array}{c}h_{\text {lmin }} \\
(\text { orifice }) \\
(\mathrm{m} / \mathrm{s})^{2}\end{array}$ & $\begin{array}{c}\Delta p_{\text {ltot }} \\
(\mathrm{Pa})\end{array}$ \\
\hline \hline 19.1 & 41.9 & 0.020 & 0.50 & 1.0 & 899 & 427 & 854 & 2,532 \\
\hline 38.2 & 9.4 & 0.024 & 0.42 & 1.0 & 18.4 & 18.4 & 43.8 & 104.3 \\
\hline 51.0 & 5.8 & 0.025 & 0.38 & 1.0 & 8.2 & 6.3 & 16.7 & 36.1 \\
\hline
\end{tabular}

The pressure drop for the $19.1 \mathrm{~mm}$ (0.75 in.) diameter tubing and elbow is shown in Table 5 to be 2,532 $\mathrm{Pa}$. Thus, the pressure drop for both the inlet and outlet adapters for one half of the MVD is simply twice this value, or 5,064 $\mathrm{Pa}$. The entire pressure drop 
through the airflow loop for one half of the MVD that the air blower must overcome is then roughly $10,600 \mathrm{~Pa}$ plus $5,064 \mathrm{~Pa}$, or $15,664 \mathrm{~Pa}$.

If both halves of the MVD are identical and receive the same air volumetric flow rate, then the air blower for the final design of the secondary air cooling system must be able to deliver an airflow rate of $0.023 \mathrm{~m}^{3} / \mathrm{s}(50 \mathrm{scfm})$ at a pressure drop of $15,664 \mathrm{~Pa}$ (59.1 in. water). Note that Table 5 lists head losses for larger diameter inlet/outlet adapters that are signif cantly lower than that for the $19.1 \mathrm{~mm}(0.75 \mathrm{in}$.) diameter version. To reduce the pressure drop in the secondary airflow loop, the inlet/outlet adapter diameter simply needs to be enlarged.

\section{Sizing of Water Chiller aind Heat Exchanger}

A single water chller and air-to-water heat exchanger are called for in the final design of the secondary cooling system for both halves (enclosures) of the MVD. Consequently, the chiller's heat removal capacity must equal or exceed that of the heat exchanger for the specified flow conditions. In addition, the heat exchanger must have an air side pressure drop of less than $6,986 \mathrm{~Pa}(1 \mathrm{psi})$ at an airflow rate of $0.030 \mathrm{~m}^{3} / \mathrm{s}$ to be consistent with that used in the prototype design of [1] and used to size the air blower. The water side pressure drop of the heat exchangers must also be consistent with the capability of the water chiller's pump.

The heat load for the enclosure forming one half of the MVD was found in [4] to be on the order of $50 \mathrm{~W}$ for an MVD operating temperature of $10^{\circ} \mathrm{C}$ and an air volumetric flow rate of $0.015 \mathrm{~m}^{3} / \mathrm{s}(32 \mathrm{cfm})$. In addition, the flow loop hardware and air blower act as additional heat loads. Heat loads on the order of $320 \mathrm{~W}$ from these sources were 
determined earlier for the primary air cooling system [1] and are expected to be similar to the heat loads for the secondary air cooling system. In summary, the total secondary system heat loads for one half of the MVD under the intended operating conditions can be broken down as follows:

- Heat load of both MVD enclosures: $100 \mathrm{~W}$

- Heat load of air blower (approximated): $60 \mathrm{~W}$

- Heat load of MVD adapters and channels (found experimentally): $200 \mathrm{~W}$

- Heat load of tubing (approximated): $60 \mathrm{~W}$

Total Heat Load $=420 \mathrm{~W}$

Using this heat load and the following operating conditions (extracted from experimental data of [4]), the heat exchangers and water chiller could be sized:

- Airflow rate: - - 0.023 standard $\mathrm{m}^{3} / \mathrm{s}(49.9 \mathrm{scfm})$

- Air temperature at heat exchanger inlet: $24^{\circ} \mathrm{C}$

- Air temperature at heat exchanger outlet: $-8^{\circ} \mathrm{C}$

- Water temperature at inlet of heat exchanger: $-2^{\circ} \mathrm{C}$

- Water flow rate: $1.26 * 10^{-4} \mathrm{~m}^{3} / \mathrm{s}(2 \mathrm{gpm})$

Sizing of Water Chiller, Dehumidifier, and Humidity Control System

A single water chiller and dehumidifier unit are required in the final design of the secondary cooling system for both halves (enclosures) of the MVD. The chiller's heat 
removal capacity must be sufficiently large at a low enough working fluid operating temperature to ensure that sufficient condensation is occurring within the dehumidifier unit to maintain the enclosure's specific humidity level within the design goal range of 0.0035 to $0.007 \mathrm{~kg} \mathrm{H}_{2} \mathrm{O} / \mathrm{kg}$ air during operation at $\mathrm{BNL}$. The chiller used in the prototype experiments [4] supplied a cooling capacity of roughly $300 \mathrm{~W}$ at a liquid coolant delivery temperature of $0^{\circ} \mathrm{C}$ for a single $\mathrm{MCD}$ enclosure. This unit worked satisfactorily in reducing the humidity in the secondary air cooling system. However, the dehumidifier unit in [4] was not insulated, which increased the heat leakage and cooling requirements of the chiller. Thus, as an extra safety measure, it is recommended that the chiller employed in the final design be capable of removing $600 \mathrm{~W}$ (for both halves of the MVD) at $-10^{\circ} \mathrm{C}$ and that the dehumidifier unit be properly insulated. These design changes will significantly increase the dehumidifying performance of the secondary air cooling system.

The prototype dehumidifier in conjunction with the air/water heat exchanger used in the enclosure air cooling tests [4], proved to be an effective means of removing moisture from the MVD's enclosure. Thus, a similar device with twice the capacity (for both enclosures) should provide the dehumidifying capabilities required by the MVD. The dehumidifier must have an air side pressure drop of less than $6,986 \mathrm{~Pa}(1 \mathrm{psi})$ at an airflow rate of $0.023 \mathrm{std} \mathrm{m}^{3} / \mathrm{s}(49.9 \mathrm{scfm})$ to be consistent with that used in the prototype design of [4] and that used to size the air blower. The water side pressure drop of the dehumidifier unit must also be consistent with the capability of the water chiller's pump.

Two different sensor/controller units are required for manipulating the humidity level inside the enclosures. A humidity probe and controller located downstream of the air-to-water heat exchanger will continuously monitor the humidity level of the air before 
entering the MVD enclosures. If the relative humidity drops below the value corresponding to a specific humidity level of $0.0035 \mathrm{~kg} \mathrm{H}_{2} \mathrm{O} / \mathrm{kg}$ air, the controller will shut off the water chiller connected to the dehumidifier unit. This will allow the humidity to rise as moisture from the dehumidifier unit is reintroduced into the circulating air. As the humidity rises above this value, the controller will turn the dehumidifier back on to allow additional condensation. The lower specific humidity limit of $0.0035 \mathrm{~kg} \mathrm{H}_{2} \mathrm{O} / \mathrm{kg}$ air was chosen because environmental humidity levels will always be larger than this value. Therefore, an additional moisture supply system will not have to be added alongside the dehumidifier unit for purposely introducing moisture to the secondary air cooling system.

Excess condensation buildup in the dehumidifier unit will be prevented by a liquid level sensor/controller and drain valve. If sufficient condensation buildup occurs on the dehumidifier's condensor coils, gravity will cause it to drip and collect at the bottom of the unit. An ultrasonic liquid level sensor will detect the pooling of the condensation and activate a solenoid drain valve located beneath the dehumidifier unit. The excess atmospheric pressure in the dehumidifier unit will force the liquid to drain out and into a collection reservoir where it will evaporate to the local environment. The dehumidifier unit must be located on the downstream (positive pressure) side of the air blower for the draining process to work correctly. In order to supply additional air to the secondary air cooling system to replace the water/air mixture lost during the draining process, an air relief solenoid valve on the upstream side of the air blower must be opened and closed concurrently with the solenoid drain valve. 


\section{Summary of Design Calculations}

Table 6 displays the design selection criteria for the individual secondary air cooling system componerts. These criteria were based upon the experimental cooling system performance data shown earlier in Table 4, the design calculations of the previous section, as well as PHEINIX operating and safety requirements. In addition to these selection criteria, there were general requirements of electrical compatibility (singlephase 120 or $240 \mathrm{~V}$ at $60 \mathrm{~Hz}$ ) with the PHENIX facility, size compatibility with storage space in the PHENIX outriggers, and reasonable costs. 
Table 6. Design selection criteria for the secondary air cooling system components.

\begin{tabular}{|c|c|}
\hline Component & Selection Criteria \\
\hline Air blower & $\begin{array}{l}\text { - Achieve a maximum flow rate of at least } 0.023 \text { standard } \mathrm{m}^{3} / \mathrm{s}(50 \mathrm{scfm}) \text { with a } \\
\text { pressure drop of at least } 15.7 \mathrm{KPa}\left(59.1 \text { in } \mathrm{H}_{2} \mathrm{O}\right) \\
\text { - Adjustable flow rate (with valve or power supply) } \\
\text { - Continuous duty with maintenance schedule of } 1 \text { year }\end{array}$ \\
\hline $\begin{array}{l}\text { Water chiller } \\
\text { (for air/water heat } \\
\text { exchanger) }\end{array}$ & $\begin{array}{l}\text { - Heat removal rate of at least } 500 \mathrm{~W} \text { at a coolant delivery temperature of } 0^{\circ} \mathrm{C} \text {. } \\
\text { - Coolant delivery temperature capability of }-10^{\circ} \mathrm{C} \text { with a stability of } \pm 0.3^{\circ} \mathrm{C} \text {. } \\
\text { - Sealed reservoir } \\
\text { - Pump flow rate capability of at least } 1.01 * 10^{-4} \mathrm{~m}^{3} / \mathrm{s}(1 \mathrm{gpm}) \text { with a pressure } \\
\text { drop of } 84 \mathrm{KPa}(12 \mathrm{psi}) \\
\text { - Continuous duty with maintenance schedule of } 1 \text { year }\end{array}$ \\
\hline $\begin{array}{c}\text { Water chiller } \\
\text { (for dehumidifier } \\
\text { unit) }\end{array}$ & $\begin{array}{l}\text { - Heat removal rate of at least } 600 \mathrm{~W} \text { at a coolant delivery temperature of }-10^{\circ} \mathrm{C} \text {. } \\
\text { - Coolant delivery temperature capability of }-20^{\circ} \mathrm{C} \text { with a stability of } \pm 0.3^{\circ} \mathrm{C} \text {. } \\
\text { - Pump flow rate capability of at least } 1.26^{*} 10^{-4} \mathrm{~m}^{3} / \mathrm{s}(2 \mathrm{gpm}) \text { with a pressure } \\
\text { drop of } 14 \mathrm{KPa}(2 \mathrm{psi}) \\
\text { - Sealed reservoir and continuous duty with maintenance schedule of } 1 \text { year }\end{array}$ \\
\hline $\begin{array}{l}\text { Air/water heat } \\
\text { exchanger }\end{array}$ & $\begin{array}{l}\text { - Heat removal rate of } 480 \mathrm{~W} \text { with the following boundary conditions: Air inlet } \\
\text { temp }=24^{\circ} \mathrm{C} \text {, air outlet temp }=8^{\circ} \mathrm{C} \text {, airflow rate }=0.023 \text { standard } \mathrm{m}^{3} / \mathrm{s}(50 \\
\text { scfm), water inlet temp }=2^{\circ} \mathrm{C} \text {, water flow rate }=1.01^{*} 10^{-4} \mathrm{~m}^{3} / \mathrm{s}(1.6 \mathrm{gpm})\end{array}$ \\
\hline Dehumidifier unit & $\begin{array}{l}\text { Capability of continuously removing moisture from the cooling system flow } \\
\text { loop. Provide a cold surface for condensation that is well below the dew point. } \\
\text { This unit should remove a majority of the moisture rather than having the } \\
\text { air/water heat exchangers performing this task. Thus, the dehumidifier's } \\
\text { condensing surface operating temperature should be } 10^{\circ} \mathrm{C} \text { less than that of the } \\
\text { heat exchanger. Surface area for condensation should be on the order of } 0.1 \\
\mathrm{~m}^{2} \text {. Will require a liquid level sensor and controller, a drain valve, and an open } \\
\text { drain reservoir. Unit should be well insulated. Specific humidity operating } \\
\text { range for BNL will be } 0.0035 \text { to } 0.007 \mathrm{~kg} \mathrm{H} \mathrm{H}_{2} \mathrm{O} / \mathrm{kg} \text { Air. }\end{array}$ \\
\hline $\begin{array}{l}\text { Humidity probe } \\
\text { and controller for } \\
\text { dehumidifier }\end{array}$ & $\begin{array}{l}\text { - Accurate control of the humidity in the flow loop is maintained by controlling } \\
\text { the power input to the dehumidifier unit and will continuously remove moisture } \\
\text { when turned on. Thus, to prevent total dryout of the secondary air cooling } \\
\text { system air, the dehumidifier's chiller must be shut off when a minimum } \\
\text { specified humidity level is reached. A humidity probe and controller located } \\
\text { downstream of the air-to-water heat exchanger will control the power supply to } \\
\text { the dehumidifer's chiller. When the humidity drops below a minimum value, } \\
\text { the chiller is shut off. When this level is exceeded, the chiller is turned on. The } \\
\text { minimum specific humidity value is } 0.0035 \mathrm{~kg} \mathrm{H} \mathrm{H}_{2} \mathrm{O} / \mathrm{kg} \text { air. }\end{array}$ \\
\hline $\begin{array}{l}\text { Tubing and } \\
\text { insulation }\end{array}$ & $\begin{array}{l}\text { - Flexible sections for routing lines and rigid sections for connecting probes. } \\
\text { - Insulated to minimize heat gains and prevent condensation. } \\
\text { - Conforms with BNL fire safety codes. }\end{array}$ \\
\hline $\begin{array}{l}\text { Liquid level sensor } \\
\text { and controller }\end{array}$ & $\begin{array}{l}\text { A liquid level sensor determines if liquid is present in the bottom of the } \\
\text { dehumidifier casing. If so, the sensor's controller activates a relay switch, } \\
\text { which then opens a solenoid valve to release the liquid from the dehumidifier } \\
\text { unit. The pressure within the dehumidifier unit must be above atmospheric for } \\
\text { this to work. An air inlet valve must be located upstream of the air blower } \\
\text { (negative atm pressure side). This valve must be opened at the same time the } \\
\text { drain valve is opened to ensure a constant mass balance of air in the loop. }\end{array}$ \\
\hline $\begin{array}{l}\text { Monitoring probes } \\
\text { (temp., airflow } \\
\text { rate, and humidity) }\end{array}$ & $\begin{array}{l}\text { - Voltage output of } 0 \text { to } 5 \mathrm{~V} \text { over the corresponding parametric range: } \\
\text { Temperature: } 0^{\circ} \mathrm{C} \text { to } 50^{\circ} \mathrm{C} \text {, relative humidity: } 5 \% \text { to } 95 \% \text {, air volumetric flow } \\
\text { rate: } 0 \text { to } 0.040 \text { standard } \mathrm{m}^{3} / \mathrm{s}(85 \mathrm{scfm} \text { ). }\end{array}$ \\
\hline
\end{tabular}




\subsubsection{Components and Costs List}

The cooling system component selections, summarized in Table 7 , were based on the design criteria presented previously. A short discussion is provided below concerning the selection of the major components, including the air blower, water chillers, heat exchanger, and dehumiditier unit. 
Table 7. Itemized list of components for the secondary air cooling system (this does not include prices for spare parts or back-up components).

\begin{tabular}{|c|c|c|c|c|}
\hline Item & $\begin{array}{l}\text { Supplier, Catalog Number, and } \\
\text { Comments }\end{array}$ & $\begin{array}{l}\text { Unit Cost } \\
\text { (No tax or } \\
\text { shipping) }\end{array}$ & Quantity & $\begin{array}{c}\text { Total Cost } \\
(\$)\end{array}$ \\
\hline $\begin{array}{l}\text { Air blower } \\
\text { (including } 5 \mathrm{hp} \\
\text { motor, 4" to 3" } \\
\text { reducer and coupler, } \\
\text { 3" to 2" reducer and } \\
\text { coupler) } \\
\end{array}$ & $\begin{array}{l}\text { Sonic Air, SAS- } 700, \\
\text { Motor }=5 \mathrm{hp}, \\
\text { Mean time between failures }=10 \text { to } \\
12 \mathrm{~K} \mathrm{~h}, \\
\text { Bearing life }=14 \mathrm{~K} \mathrm{~h}, \text { Drive belt }=6 \\
\mathrm{~K} \mathrm{~h}, \text { Motor life }=5 \text { to } 7 \mathrm{y}\end{array}$ & 2,782 & 1 & 2,782 \\
\hline $\begin{array}{l}\text { Water chiller } \\
\text { (for air/water heat } \\
\text { exchanger) }\end{array}$ & $\begin{array}{l}\text { FTS Systems, RS33, } 610 \mathrm{~W} \text { at } 0^{\circ} \mathrm{C} \\
\text { with positive displacement pump, } \\
\text { Coolant temperature range }= \\
-10^{\circ} \mathrm{C} \text { to } 35^{\circ} \mathrm{C} \text {, } \\
\text { Coolant flow }=1.6 \mathrm{gpm} \text { at } 100 \mathrm{psi}\end{array}$ & 2,610 & 1 & 2,610 \\
\hline $\begin{array}{l}\text { Water chiller } \\
\text { (for dehumidifier) }\end{array}$ & $\begin{array}{l}\text { FTS Systems, RS44LT, } 670 \mathrm{~W} \text { at } \\
-10^{\circ} \mathrm{C} \text {, } \\
\text { Coolant temperature range }= \\
-40^{\circ} \mathrm{C} \text { to } 35^{\circ} \mathrm{C} \text {, } \\
\text { Coolant flow }=2 \mathrm{gpm} \text { at } 6 \mathrm{psi} \\
\end{array}$ & 3,085 & 1 & 3,085 \\
\hline $\begin{array}{l}\text { Air/water heat } \\
\text { exchanger }\end{array}$ & $\begin{array}{l}\text { Lytron, } 6110 \text {, } \\
\text { Lytron to supply heat exchanger } \\
\text { cores. A machine shop vendor is } \\
\text { required to fabricate heat exchanger } \\
\text { casing. }\end{array}$ & & & \\
\hline Dehumidifier unit & This unit must still be designed. & & & \\
\hline Humidity controller & $\begin{array}{l}\text { Omega, CN3230-P1-P1-1, with } 2 \\
\text { PR-11-2-100-1/8-9-E RTD probes, } \\
\text { and an optional } 1 \text { to } 5 \mathrm{Vdc} \text { output, } \\
\text { Range }=3 \% \text { to } 95 \% \text { RH, } \\
\text { (temperature compensated), } \\
\text { Input }=120 \mathrm{Vac} \text {, } \\
\text { Output }=1 \text { to } 5 \mathrm{Vdc}, \\
\text { Optional RS port for digital } \\
\text { communication. }\end{array}$ & 1,412 & 1 & 1,412 \\
\hline Liquid level sensor & $\begin{array}{l}\text { Omega, LVU-232S, } \\
\text { Input }=120 \mathrm{Vac}\end{array}$ & 399 & 1 & 399 \\
\hline Solenoid valve & Omega, SV-601, Input $=120 \mathrm{Vac}$ & 78 & 1 & 78 \\
\hline Air velocity meter & $\begin{array}{l}\text { Omega, FMA-905-V, } \\
\text { Range }=10 \text { to } 5000 \text { SFPM, } \\
\text { Input }=15 \text { to } 24 \mathrm{Vdc} \text {, } \\
\text { Output }=0 \text { to } 5 \mathrm{Vdc} \text {, }\end{array}$ & 822 & 1 & 822 \\
\hline $\begin{array}{l}\text { Humidity and } \\
\text { temperature sensor }\end{array}$ & 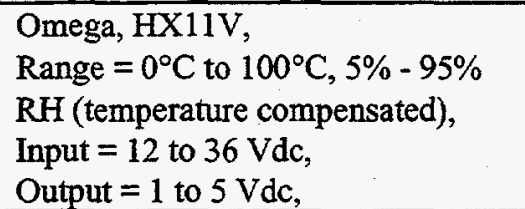 & 205 & 2 & 410 \\
\hline Tubing and fittings & $\begin{array}{l}\text { Accurate Plastics, } \\
\text { Albuquerque Valve and Fitting Co. }\end{array}$ & & & \\
\hline Insulation & Grainger & & & \\
\hline Total & 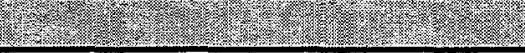 & & 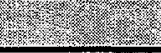 & $(11,598)$ \\
\hline
\end{tabular}




\section{Air Blower}

As was done for the primary air cooling system, the Sonic SAS-700 blower was chosen for the secondary air cooling system because of its high performance, long lifetime over continuous operation, and relatively low cost. The brake horsepower and discharge pressure curves versus airflow rate for various rpms were shown previously in Figure 5. To provide a flow rate of 0.023 standard $\mathrm{m}^{3} / \mathrm{s}(50 \mathrm{scfm})$ while handling a pressure drop of $15.7 \mathrm{KPa}\left(59.1\right.$ in $\mathrm{H}_{2} \mathrm{O}$ ), a $5 \mathrm{hp}$ (or greater) motor is required to provide a sufficient safety cushion. Other beneficial features include the small size of the unit $\left(56 * 30 * 57 \mathrm{~cm}^{3}\right)$ that allows it to fit within the PHENIX outrigger supports, the availability of inlet and outlet adapters to fit $50.8 \mathrm{~mm}$ ( 2 in.) tubing, a belt drive to eliminate heat dumping from the motor to the airflow, and long component lifetimes (see Table 7).

\section{Water Chiller for Heat Eschanger}

A single FTS Systems RS33 water chiller, with the positive displacement pump and external high pressure bypass options, was selected to remove the waste heat from the secondary air cooling system heat exchanger $(480 \mathrm{~W})$. The RS33 with the positive displacement pump has a heat rate removal capacity of $610 \mathrm{~W}$ at a $0^{\circ} \mathrm{C}$ coolant temperature and a minimum coolant supply temperature of $-10^{\circ} \mathrm{C}$ with a temperature stability of $\pm 0.1^{\circ} \mathrm{C}$. The sealed reservoir holds 4 liters of coolant, and the positive displacement pump will deliver a coolant flow rate of $1.01 * 10^{-4} \mathrm{~m}^{3} / \mathrm{s}(1.6 \mathrm{gpm})$ at a pressure drop of $698.7 \mathrm{KF} a(100 \mathrm{psi})$. The overall dimensions $\left(33.0 * 53.3 * 48.3 \mathrm{~cm}^{3}\right)$ are small enough to allow the chiller to be positioned within the openings in the PHENIX 
outrigger supports. Finally, the waste heat from the chiller is removed to the environment by a fan. However, air conditioning systems in the PHENIX Major Facility Hall will effectively transfer this waste heat to the outer environment. The RS33 requires a $120 \mathrm{~V}$ single phase input at $60 \mathrm{~Hz}$ and draws $8 \mathrm{~A}$.

\section{Heat Exchanger}

The air-to-water heat exchanger for the secondary air cooling system is identical to that for the primary air cooling system, shown previously in Figure 6. Two copper tube and fin heat exchanger cores (model 6110) provided by Lytron, Inc., will be encased within an insulated shell enclosure through which the coolant airflows. Coolant water, supplied by the RS33 water chiller, will pass through the tubes of each core and remove heat through extended fins from the airflow stream. The thermal performance, air side pressure drop, and water side pressure drop curves for a single 6110 heat exchanger core were shown earlier in Figures 7(a) through 7(c). Using the operating criteria presented earlier for the heat exchanger $\left(0.023\right.$ standard $\mathrm{m}^{3} / \mathrm{s}(50 \mathrm{scfm})$ airflow rate, $24^{\circ} \mathrm{C}$ air inlet temperature, $8^{\circ} \mathrm{C}$ air outlet temperature, $2^{\circ} \mathrm{C}$ water outlet temperature, $1.01 * 10^{-4} \mathrm{~m}^{3} / \mathrm{s}(1.6$ gpm) water flow rate, and a heat exchanger sizing scheme provided by Lytron, the thermal performance curves of several different heat exchanger cores were investigated. A thermal performance of $22 \mathrm{~W} /{ }^{\circ} \mathrm{C}$ was needed to satisfy the cooling requirements for the secondary air cooling system. A single 6110 heat exchanger core operating at an airflow rate of $50 \mathrm{scfm}$ and a water flow rate of $1.6 \mathrm{gpm}$ has a thermal performance of $17 \mathrm{~W} /{ }^{\circ} \mathrm{C}$. Thus, a decision was made to use two 6110 heat exchanger cores operating in series that 
would easily deliver the required cooling performance. For one secondary air cooling system heat exchanger, two 6110 heat exchanger cores operating in series at the specified flow rates would result in air and water side pressure drops of 0.009 psi and 7 psi, respectively. These pressure drops can be sufficiently handled by the air blower and water chiller pump.

\section{Water Chiller for Dehumidifier}

A single FTS Systems RS44LT water chiller, with the standard centrifugal pump, was selected to remove the waste heat from the secondary air cooling system heat exchanger $(600 \mathrm{~W})$. The RS33 with the standard pump has a heat rate removal capacity of $680 \mathrm{~W}$ at a $-10^{\circ} \mathrm{C}$ coolant temperature and a minimum coolant supply temperature of $-40^{\circ} \mathrm{C}$ with a temperature stability of $\pm 0.1^{\circ} \mathrm{C}$. The sealed reservoir holds 4 liters of coolant, and the centrifugal pump will deliver a coolant flow rate of $1.26^{*} 10^{-4} \mathrm{~m}^{3} / \mathrm{s}(2.0$ $\mathrm{gpm})$ at a pressure drop of $41.9 \mathrm{KPa}(6 \mathrm{psi})$. The overall dimensions $(33.0 * 53.3 * 48.3$ $\mathrm{cm}^{3}$ ) are small enough to allow the chiller to be positioned within the openings in the PHENIX outrigger supports. Finally, the waste heat from the chiller is removed by a fan to the environmental air. However, air conditioning systems in the PHENIX Major Facility Hall will effectively transfer this waste heat to the outer environment. The RS44LT requires a 208 to $230 \mathrm{~V}$ single phase input at $60 \mathrm{~Hz}$ and draws $7 \mathrm{~A}$.

\section{Dehumidifier Unit}

A proposed dehumidifier design that is fairly similar to the prototype used in [4] is shown in Figure 9. An insulated stainless steel vessel forms the outer casing of the 


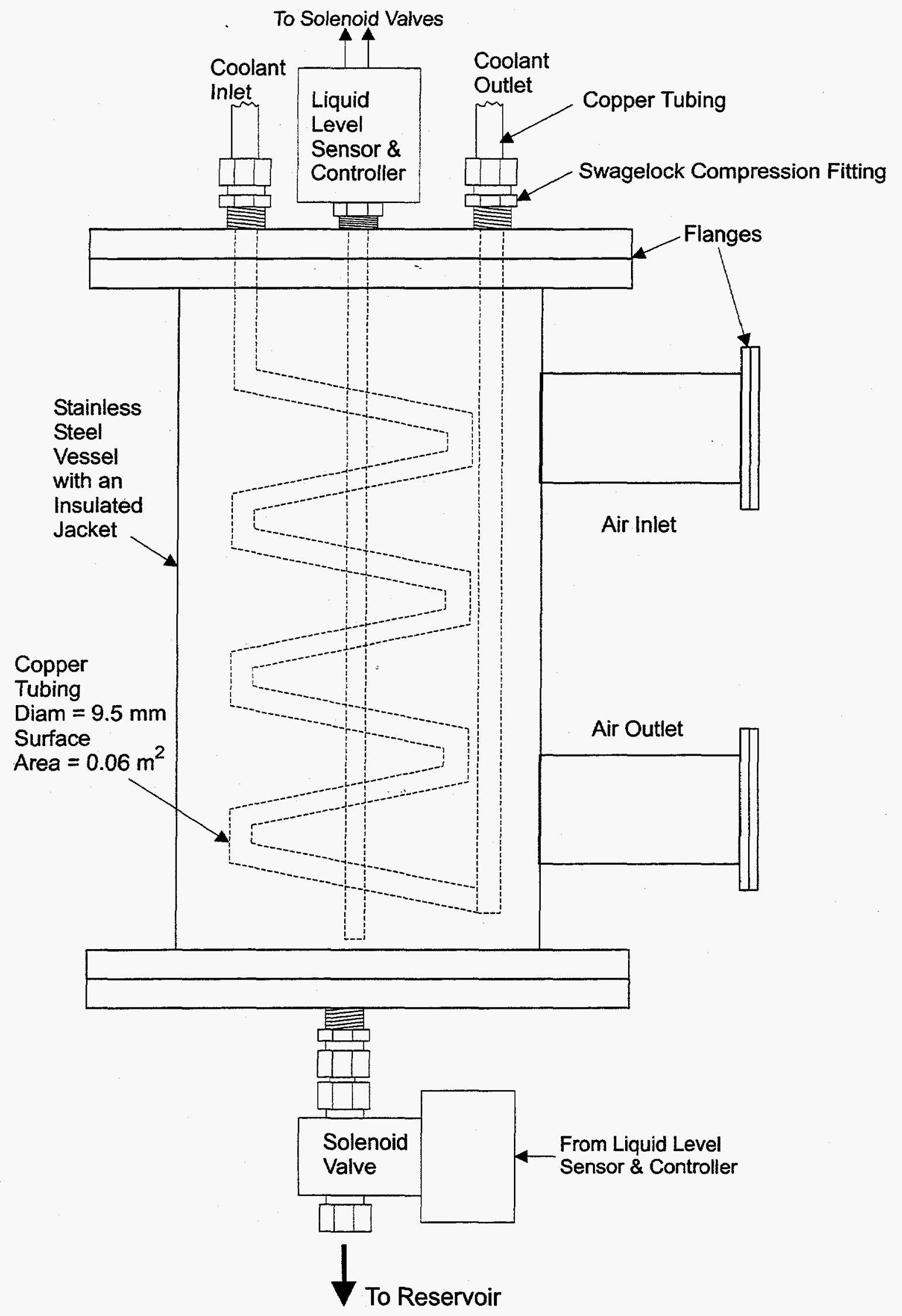

Figure 9. Schematic diagram of the dehumidifier unit for the secondary air cooling system. 
unit. Two ports on the side of the vessel serve as an inlet and outlet for the circulating airflow. A wound length of $9.5 \mathrm{~mm}(0.375 \mathrm{in}$.) diameter copper refrigeration tubing with a surface area of roughly $0.06 \mathrm{~m}^{2}$ enters and leaves the top flange of the vessel by two compression fittings. The coolant water/antifreeze mixture necessary for condensation flows through the coppes: tubing. Condensation will form on the outer surface of the copper tubing and flow to the bottom of the vessel by the action of gravity. Potential excess water buildup in the dehumidifier unit will be prevented by a liquid detection/release scheme. A liquid level sensor/controller will detect if the condensate buildup becomes appreciable, and if so, activate a solenoid drain valve at the bottom of the vessel. Excess water will exit the drain valve and into an open-air reservoir where it will evaporate to the environment in the PHENIX Major Facility Hall. To prevent the backflow of air into the vessel during operation of the draining process, the dehumidifier unit must be placed on the positive pressure side of the secondary air cooling system; between the air blower and the MVD. To balance the airflow out of the dehumidifier unit during the draining processs, a second solenoid valve, located just upstream of the air blower, must be opened simultaneously with the drain valve solenoid to allow an equal inflow of air.

\section{Instrumentation}

An HX11V prote from Omega was chosen to provide relative humidity (temperature compensated) and temperature measurements of the primary air cooling system air exiting the air-to-water heat exchanger. This unit has relative humidity and temperature ranges of $5 \%$ to $95 \%( \pm 2 \%)$ and $0^{\circ} \mathrm{C}$ to $100^{\circ} \mathrm{C}\left( \pm 0.6^{\circ} \mathrm{C}\right)$, respectively. The 
probe gives a linear direct voltage output of 1 to $5 \mathrm{Vdc}$ for both relative humidity and temperature. The sensors are placed in a stainless steel (316SS) watertight sheath that has a $130 \mathrm{~mm}(5.1 \mathrm{in}$.) length and a $16 \mathrm{~mm}(0.625 \mathrm{in}$.) diameter. A compression fitting will be required to mount the sensor in the center of the airflow line downstream of the heat exchanger. The sensor will require a direct current input voltage in the range of 12 to 36 Vdc for operation.

An Omega (FMA-905-V) hot wire anemometer with a range of 10 to $5,000 \mathrm{sfpm}$ $( \pm 1.5 \%)$ will be used to monitor the mean airflow velocity at the same location as the temperature/humidity measurements. The volumetric airflow rate can be determined by multiplying the mean airflow velocity by the cross-sectional area of the pipe at the instrument's location. The probe gives a linear direct voltage output of 0 to $5 \mathrm{Vdc}$ for air velocity. The hot wire sensor is placed in a stainless steel (316SS) sheath that has a 330 mm (13 in.) length and a $6.35 \mathrm{~mm}(0.250$ in.) diameter. A compression fitting will be required to mount the sensor in the center of the airflow line downstream of the heat exchanger. The sensor will require a direct current input voltage in the range of 15 to 24 Vdc for operation.

\section{Tubing, Fittings, and Insulation}

Accurate Plastics Inc. and Albuquerque Valve and Fitting have been chosen as the suppliers of tubing and fittings. Accurate Plastics can provide both rigid and flexible tubing for the airflow lines and Albuquerque Valve and Fitting can supply the compression fittings needed for installing the instrumentation. Grainger, a vendor for industrial equipment and supplies, has a large variety of insulation tapes and pipe sleeves. 
Fire code criteria for these insulation materials are specified by the vendor. Because the exact placement of components and routing of coolant lines has not yet been determined, the precise amount of tubing, fittings, and insulation cannot be determined at this point in time.

\subsubsection{Safety Measures}

Several safety measures have been included in the final secondary air cooling system design to ensure proper operating performance of the silicon strip detectors in the MVD enclosures. These measures are as follows:

- A lower design goal of temperature limit of $10^{\circ} \mathrm{C}$ for the MVD enclosure was used to base the cooling requirements for the air cooling system. This design goal is conservatively $10^{\circ} \mathrm{C}$ below the maximum operating temperature limit of $20^{\circ} \mathrm{C}$.

- The air blower, water chillers, and heat exchanger selected for the final design were oversized to allow a cushion in the available cooling power and dehumidifying capabilities should abriormal conditions arise.

- The water chiller for the dehumidifier is designed with a lower liquid delivery temperature limit of $-40^{\circ} \mathrm{C}$ should higher condensation rates be required in the dehumidifier unit beyond those anticipated with a $-10^{\circ} \mathrm{C}$ liquid delivery temperature.

\subsubsection{System Operation}

The setup and operation of the secondary air cooling system will proceed as follows: 
1. The blower is turned on and the flow rate adjusted manually by opening or closing a throttling valve until the desired flow rate of 0.023 standard $\mathrm{m}^{3} / \mathrm{s}(50 \mathrm{scfm})$ (corresponds to an standard air velocity of $2290 \mathrm{fpm}$ in a 2 in. pipe) is obtained, as displayed by the air velocity probe.

2. The water chiller for the air-to-water heat exchanger will be activated and adjusted manually until the desired MVD inlet air temperature of $8^{\circ} \mathrm{C}$ is achieved, as determined with the aid of the temperature probe and display.

3. The water chiller for the dehumidifier unit will be set for a liquid supply temperature of $-10^{\circ} \mathrm{C}$ to begin dehumidification of the airflow. A liquid level sensor and valve will automatically remove excess moisture from the dehumidifier unit should it be required. The humidity controller will shut off the dehumidifier unit's water chiller once the lower specific humidity limit of $0.0035 \mathrm{~kg} \mathrm{H}_{2} \mathrm{O} / \mathrm{Kg}$ air is reached and will turn it back on as this value is exceeded. This system is fully versatile and can be changed to any desired operating humidity level.

4. Fine adjustment of the flow rate and the heat exchanger's chiller temperature will be required once the MVD electronics have been turned on and allowed to reach steadystate operation. In addition, some assessment of the final manual settings will have to be made based on the present temperature and humidity values within the PHENDX Major Facility Hall. 


\subsection{Liquid Cooling System for Low Dropout Voltage Regulators}

The liquid cooling system will serve to cool the LDOs by a combined conduction and forced convection scheme. Heat will be conducted away from the LDOs and through the motherboard by thermal vias to a coolant tube mounted on the opposite side. The coolant, FC-75, will be passed through the aluminum coolant tube to collect the waste heat from the thermal vias. A complete description of experimental testing of a prototype liquid cooling system for the MVD's LDOs can be found in [3], and therefore only a summary of the performance characteristics will be presented here.

Before the experiments, the design criteria for the LDOs were defined as follows:

- Maximum allowable LDO operating temperature $125^{\circ} \mathrm{C}$

- Cooling system design :goal for maximum LDO operating temperature$40^{\circ} \mathrm{C}$

- Maximum power dissipation of a single LDO $1.0 \mathrm{~W}$

- Cooling liquid supply temperature $5^{\circ} \mathrm{C}$ to $10^{\circ} \mathrm{C}$

- Dimensions of LDO main body $9.0 \mathrm{~mm}(\mathrm{H})$ by $10.4 \mathrm{~mm}(\mathrm{~L})$ by $4.5 \mathrm{~mm}(\mathrm{~T})$

As described in $\left[\begin{array}{l}{[3]} \\ ]\end{array}\right]$ a prototype of the motherboard, LDOs, and coolant supply system was used with the design specifications listed above to assess the operating performance of the liquid cooling system. In particular, LDO operating temperatures were measured for various: $\mathrm{LDO} /$ coolant tubing junction configurations and liquid coolant supply temperatures. Tatble 8 summarizes the LDO operating temperatures for various LDO coolant tubing junction configurations with an individual LDO power dissipation of $1 \mathrm{~W}$ and a water flow rate of $220 \mathrm{~cm}^{3} / \mathrm{min}$. 
Table 8. Summary of the LDO operating temperatures for various LDO coolant tubing junction configurations with an individual LDO power dissipation of $1 \mathrm{~W}$ and a water flow rate of $220 \mathrm{~cm}^{3} / \mathrm{min}$.

\begin{tabular}{|c|c|c|c|c|c|}
\hline $\begin{array}{c}\text { LDO/ } \\
\text { Coolant } \\
\text { Tube } \\
\text { Config. } *\end{array}$ & $\begin{array}{c}\text { Inlet } \\
\text { Water } \\
\text { Temp. } \\
\left({ }^{\circ} \mathrm{C}\right)\end{array}$ & $\begin{array}{c}\text { Outlet } \\
\text { Water } \\
\text { Temp. } \\
\left({ }^{\circ} \mathrm{C}\right)\end{array}$ & $\begin{array}{c}\text { LDO \#1 } \\
\text { Temp. } \\
\left({ }^{\circ} \mathrm{C}\right)\end{array}$ & $\begin{array}{c}\text { LDO \#2 } \\
\text { Temp. } \\
\left({ }^{\circ} \mathrm{C}\right)\end{array}$ & $\begin{array}{c}\text { LDO \#3 } \\
\text { Temp. } \\
\left({ }^{\circ} \mathrm{C}\right)\end{array}$ \\
\hline \hline 1 & 6.6 & $>10.0$ & $>70$ & $>70$ & $>70$ \\
\hline 2 & 6.6 & 8.1 & 40.0 & 40.9 & 47.6 \\
\hline 3 & 5.1 & 6.4 & 32.7 & 27.2 & 32.0 \\
\hline 3 & 6.4 & 7.9 & 32.6 & 27.1 & 34.8 \\
\hline 3 & 9.9 & 11.1 & 36.3 & 31.4 & 36.5 \\
\hline 4 & 5.0 & 5.4 & 37.6 & 38.4 & 38.6 \\
\hline 4 & 10.2 & 10.5 & 40.6 & 41.6 & 41.9 \\
\hline
\end{tabular}

* 1. LDO in direct contact with round tubing, no motherboard, no adapter.

2. LDO in direct contact with flat tubing, no motherboard, no adapter.

3. LDO in direct contact with round tubing with interface adapter, no motherboard.

4. LDO in contact with flat tubing, separated by the motherboard and thermal vias.

\subsubsection{System Description and Design Specifications}

The final design of the liquid cooling system for the MVD's LDOs is shown schematically in Figure 10. This system will cool all four sets (four motherboards) of fifteen LDOs each and require a single flow loop. The liquid cooling system consists of a liquid chiller containing the circulating pump, liquid reservoir, and pressure relief valve, a vacuum pump for liquid loading operations, insulated tubing, and a monitoring probe for temperature. FC-75, a dielectric produced by the $3 \mathrm{M}$ corporation, was chosen as the working fluid for the liquid cooling system.

\section{Sizing of Liquid Chiller}

The liquid chiller must have enough cooling capacity to remove the waste heat from the LDOs as well as environmental heat loads on the tubing and fittings. 


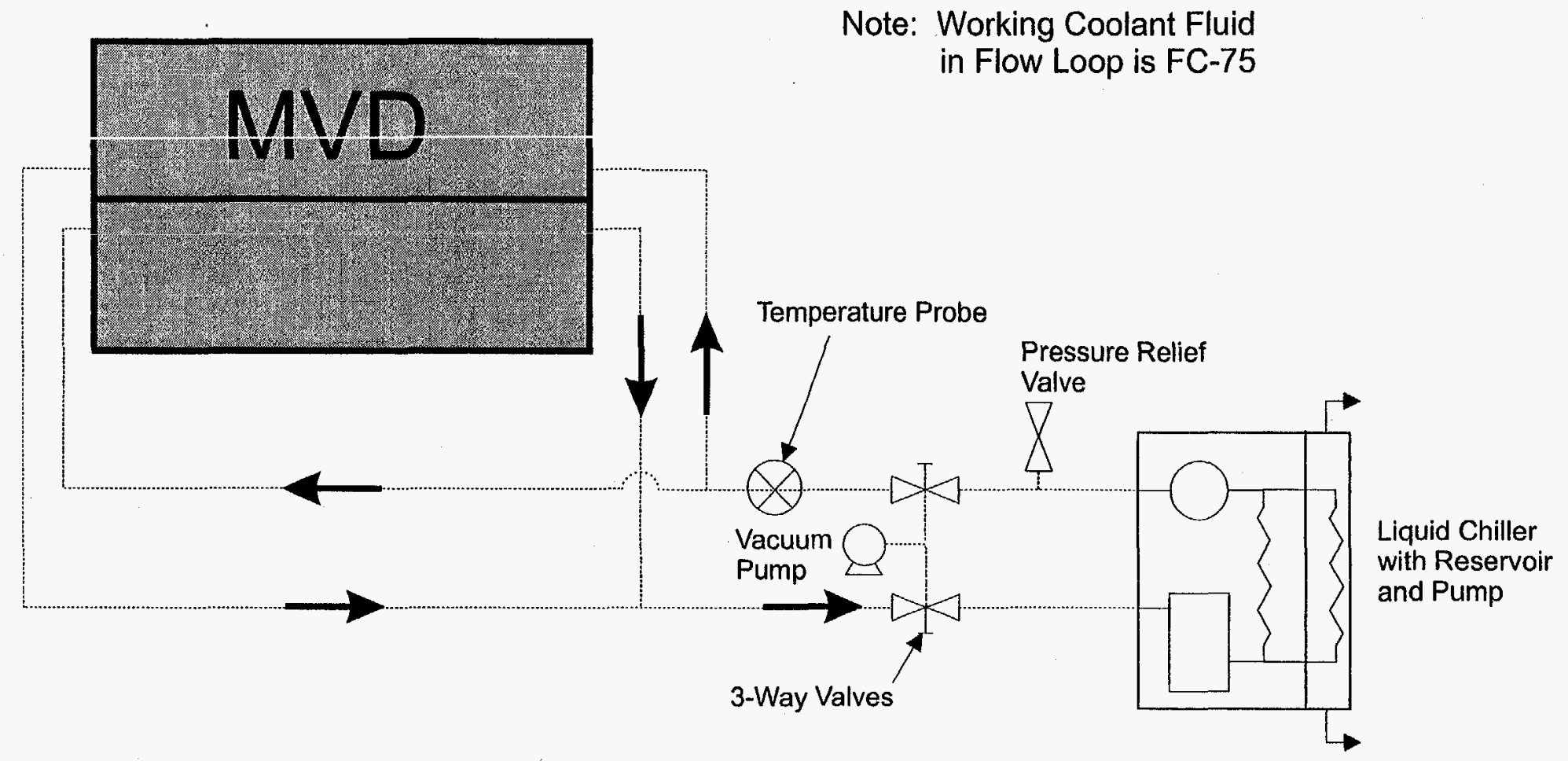

Figure 10. Schematic diagram of the MVD's liquid cooling system for the low dropout voltage regulators. 
The maximum designed heat load imposed by the $60 \mathrm{LDOs}$ is $60 \mathrm{~W}$. Assuming an environmental heat load on the order of 20 to $40 \mathrm{~W}$, a cooling capacity greater than or equal to $100 \mathrm{~W}$ is required. In addition, from the experimental data presented above, a liquid supply temperature of $5^{\circ} \mathrm{C}$ is required to ensure that $\mathrm{LDO}$ temperatures are below the $40^{\circ} \mathrm{C}$ designed operating limit. In the prototype LDO cooling experiments [3], water was used as the working fluid at a volumetric flow rate of $220 \mathrm{~cm}^{3} / \mathrm{min}$. Calculations provided in [3] indicated that to achieve the same thermal performance with FC-75 as was obtained with water, a volumetric flow rate of $1760 \mathrm{~cm}^{3} / \mathrm{min}$ would be required in the cooling system containing the FC-75. The pressure drop through the liquid lines can be determined with the aid of Equation (10). Assuming that $9.5 \mathrm{~mm}(0.375 \mathrm{in}$.) tubing with a length of $50 \mathrm{~m}(164 \mathrm{ft})$ is used for the liquid flow lines (except for the short sections connected to the motherboards) and an FC-75 flow rate of $1760 \mathrm{~cm}^{3} / \mathrm{min}$, a pressure drop of approximately $75 \mathrm{KPa}(10.7 \mathrm{psi})$ would exist.

In summary, the liquid chiller must be able to remove at least $100 \mathrm{~W}$ of waste heat, supply coolant at or below $5^{\circ} \mathrm{C}$ to the MVD at a flow rate of at least $1760 \mathrm{~cm}^{3} / \mathrm{min}$ (0.46 gpm), and overcome a pressure drop of $75 \mathrm{KPa}(10.7 \mathrm{psi})$

\section{Sizing of Vacuum Pump}

A roughing vacuum pump is required to remove the majority of the air from the coolant lines before loading the FC-75. By first pumping out the coolant lines, the FC-75 can then be drawn in simply by opening a valve connecting the lines to the liquid reservoir. The maximum vertical height that a liquid can be drawn up a tube by a vacuum against gravity (neglecting surface tension effects) is given by 


$$
h=\frac{\Delta P}{\rho g},
$$

where $\Delta P$ is the pressure difference between the atmosphere at the base of the tube and the vacuum pressure at the top of the liquid column, $\rho$ is the liquid density, and $g$ is the gravitational constant.

If a vacuum pump is used to reduce the pressure in the coolant lines to $1 \mathrm{KPa}(7.5$ torr), then using an atmospheric pressure of $101.3 \mathrm{KPa}$ (760 torr) and an FC-75 fluid density of $1770 \mathrm{Kg} / \mathrm{m}^{3}$, the maximum height that the FC-75 liquid can be drawn up in a vertical direction from the reservoir is $5.8 \mathrm{~m}(19.0 \mathrm{ft})$. Further reduction in the line

pressure would not lead to significant gains in the pumping height. Consequently, a conventional roughing pump will satisfy the vacuum requirements for loading the FC-75 into the coolant lines.

\section{Summary of Design Calculations}

Table 9 displays the design selection criteria for the individual liquid cooling system components. These criteria were based upon the experimental cooling system performance data shown earlier in Table 8 , the design calculations of the previous section, as well as PHENIX operating and safety requirements. In addition to these selection criteria, there were general requirements of electrical compatibility (single phase 120 or $240 \mathrm{~V}$ at $60 \mathrm{~Hz}$ ) with the PHENIX facility, size compatibility with storage space in the PHENIX outriggers, and reasonable costs. 
Table 9. Design selection criteria for the LDO liquid cooling system components.

\begin{tabular}{|c|c|}
\hline Component & Selection Criteria \\
\hline Water chiller & $\begin{array}{l}\text { - Heat removal rate of at least } 100 \mathrm{~W} \text { at a coolant delivery } \\
\text { temperature of } 5^{\circ} \mathrm{C} \text {. } \\
\text { - Coolant delivery temperature capability of } 0^{\circ} \mathrm{C} \text { with a stability of } \\
\pm 0.3^{\circ} \mathrm{C} \text {. } \\
\text { - Sealed reservoir. } \\
\text { - Pump flow rate capability of at least } 0.63^{*} 10^{-4} \mathrm{~m}^{3} / \mathrm{s}(1 \mathrm{gpm}) \text { with } \\
\text { a pressure drop of } 75 \mathrm{KPa}(10.7 \mathrm{psi}) \text { for } \mathrm{FC}-75 \text {. } \\
\text { - Continuous duty with maintenance schedule of } 1 \text { year. } \\
\text { - Pressure relief valve. }\end{array}$ \\
\hline Vacuum pump & $\begin{array}{l}\text { Roughing pump capable of lowering line pressure down to } 1 \mathrm{KPa} \\
\text { (7.5 torr) before filling lines with FC- } 75 \text {. This will allow the FC- } \\
75 \text { to climb to a height of } 5.8 \mathrm{~m}(19.0 \mathrm{ft}) \text { in order to fill the } \\
\text { coolant lines from the reservoir to the endplates. The relatively } \\
\text { low volume of the coolant lines and the relatively high target } \\
\text { pressure of } 1 \mathrm{KPa}(7.5 \text { torr) are such that the pumping speed of a } \\
\text { conventional roughing pump will not be a major factor in } \\
\text { determining the loading time for the FC- } 75 \text {. }\end{array}$ \\
\hline Coolant tubing & - Good heat conductor that is easily machined and formed. \\
\hline Tubing and insulation & $\begin{array}{l}\text { - Flexible sections for routing lines. Lines must not collapse under } \\
\text { Vacuum prior to filling lines with FC-75. } \\
\text { - Rigid sections for connecting monitoring probes. } \\
\text { - Insulated to minimize heat gains and prevent condensation. } \\
\text { - Conforms with BNL fire safety codes. }\end{array}$ \\
\hline $\begin{array}{l}\text { Temperature monitoring } \\
\text { probe }\end{array}$ & $\begin{array}{l}\text { - Voltage output of } 1 \text { to } 5 \mathrm{~V} \text { over the corresponding parametric } \\
\text { range: Temperature: } 0^{\circ} \mathrm{C} \text { to } 50^{\circ} \mathrm{C} \text {. }\end{array}$ \\
\hline
\end{tabular}

\subsubsection{Components and Costs List}

The liquid cooling system component selections, summarized in Table 10, were based on the design criteria presented previously. A short discussion is provided below concerning the selection of the major components, including the liquid chiller, working fluid, vacuum pump, and coolant tubing. 
Table 10. Itemized list of components for the liquid cooling system (this does not include prices for spare parts or back-up components).

\begin{tabular}{|c|c|c|c|c|}
\hline Item & $\begin{array}{l}\text { Supplier, Cat. \#, } \\
\text { Comments }\end{array}$ & $\begin{array}{l}\text { Unit Cost } \\
\text { (No tax or } \\
\text { shipping) }\end{array}$ & Quantity & $\begin{array}{c}\text { Total Cost } \\
(\$)\end{array}$ \\
\hline Water chiller & $\begin{array}{l}\text { FTS systems, } \mathrm{RS} 33,610 \mathrm{~W} \text { at } \\
0^{\circ} \mathrm{C} \text { with positive displacement } \\
\text { pump option, } \\
\text { Coolant temp. range }= \\
-10^{\circ} \mathrm{C} \text { to } 35^{\circ} \mathrm{C} \text {, } \\
\text { Coolant flow }=1.6 \mathrm{gpm} \text { at } 100 \\
\text { psi }\end{array}$ & 2,440 & 1 & 2,440 \\
\hline $\begin{array}{l}\text { FC-75 fluorinert } \\
\text { liquid }\end{array}$ & $\begin{array}{l}\text { 3m Electronic Products } \\
\text { Division, } \mathrm{FC}-75 \\
\text { At atm pressure, boiling temp. } \\
=102^{\circ} \mathrm{C} \text {, } \\
\text { pour temp. }=-88^{\circ} \mathrm{C} \text {, } \\
\text { density }=1770 \mathrm{~kg} / \mathrm{m}^{3} \\
\text { dielectric const. }=1.86\end{array}$ & $41 / 1 b$ & $\begin{array}{c}44 \mathrm{lb} \\
(3 \mathrm{gal} .)\end{array}$ & 1,804 \\
\hline Vacuum pump & $\begin{array}{l}\text { Leybold, TriVac E Rotary } \\
\text { Vane Pump without gas } \\
\text { ballast, T1-21111233 } \\
\text { Pumping speed }=1.9 \mathrm{cfm} \text { from } \\
1<\mathrm{P}<760 \text { torr }\end{array}$ & 1,190 & 1 & 1,190 \\
\hline $\begin{array}{l}\text { Coolant tubing in } \\
\text { motherboard }\end{array}$ & $\begin{array}{l}\mathrm{Al}-1100,0.25 \text { in drawn tubing, } \\
\text { Fabrication process conducted } \\
\text { by Hand Precision Machining, } \\
\text { Inc. }\end{array}$ & 50 & 4 & 200 \\
\hline $\begin{array}{l}\text { Temperature } \\
\text { probe }\end{array}$ & $\begin{array}{l}\text { Omega, DP41-TC-A, with } \\
\text { KMTiSS-125G-6 type K } \\
\text { thermocouple, } \\
\text { Input }=120 \mathrm{Vac} \text {, } \\
\text { Outprt }=0 \text { to } 5 \mathrm{Vdc} \text {, } \\
\text { Optional RS port and relays } \\
\text { for control option. }\end{array}$ & 729 & 1 & 729 \\
\hline $\begin{array}{l}\text { Tubing and } \\
\text { fittings }\end{array}$ & $\begin{array}{l}\text { Accurate Plastics, } \\
\text { Albucuerque Valve and } \\
\text { Fitting, } \\
\text { Tubing must be able to support } \\
\text { a vacium. }\end{array}$ & & & \\
\hline $\begin{array}{l}\text { Pressure relief } \\
\text { valve }\end{array}$ & $\begin{array}{l}\text { Albucuerque Valve and Fitting } \\
\text { Co., SS-4R3A-A }\end{array}$ & 100 & 1 & 100 \\
\hline Insulation & Grainger & & & \\
\hline Total - & 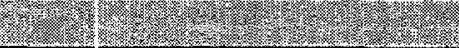 & & 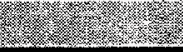 & $(6,463)$ \\
\hline
\end{tabular}




\section{Liquid Chiller}

A single FTS Systems RS33 liquid chiller, with the positive displacement pump was selected to remove the waste heat from the liquid cooling system $(100 \mathrm{~W})$. The RS33 with the positive displacement pump, has a heat rate removal capacity of $610 \mathrm{~W}$ at a $0^{\circ} \mathrm{C}$ coolant temperature and a minimum coolant supply temperature of $-10^{\circ} \mathrm{C}$ with a temperature stability of $\pm 0.1^{\circ} \mathrm{C}$. The sealed reservoir holds 4 liters of coolant and the positive displacement pump will deliver a coolant flow rate of $1.01 * 10^{-4} \mathrm{~m}^{3} / \mathrm{s}(1.6 \mathrm{gpm})$ at a pressure drop of $698.7 \mathrm{KPa}(100 \mathrm{psi})$. The overall dimensions $\left(33.0 * 53.3 * 48.3 \mathrm{~cm}^{3}\right)$ are small enough to allow the chiller to be positioned within the openings in the PHENIX outrigger supports. Finally, the waste heat from the chiller is removed to the environment by a fan. However, air conditioning systems in the PHENIX Major Facility Hall will effectively transfer this waste heat to the outer environment. The RS33 requires a $120 \mathrm{~V}$ single-phase input at $60 \mathrm{~Hz}$ and draws $8 \mathrm{~A}$.

\section{Working Fluid}

FC-75 was chosen as the working fluid for the liquid cooling system to reduce the complexity of the design and risk of electrical damage caused by coolant leakage. This liquid has an extremely low dielectric constant $\left(1.86\right.$ at $\left.25^{\circ} \mathrm{C}\right)$ that significantly reduces the chances of electrical shortages should the liquid leak out onto electrical components. As a result, a complicated 'leak-less' system design is not necessary for the liquid cooling system flow loop. $\mathrm{FC}-75$ has a boiling point of $102^{\circ} \mathrm{C}$ (at standard pressure) that is sufficiently high to prevent boiling in the present system. As an extra safety measure, a 
pressure relief valve is included in the flow loop in the unlikely situation that boiling and a corresponding high pressure situation develop. In addition, the pour point for FC-75 is $-88^{\circ} \mathrm{C}$, well below the intended operating temperature of $5^{\circ} \mathrm{C}$. The viscosity of $\mathrm{FC}-75$ is approximately equivalent and its liquid density is approximately $75 \%$ greater than that of water. FC-75 is a fluorocarbon fluid that is nonflammable, nonexplosive, nontoxic, compatible with metals, plastics, and elastomers, and is non-damaging to the stratospheric ozone layer [no Chloro-flouro carbons (CFCs)].

\section{Vacuum Pump}

A Leybold TriVac. E T1-21111233 rotary vane pump was selected to perform the rough vacuum pumping of the liquid coolant lines. This pump will maintain a relatively constant pumping speed of $8.9 * 10^{-4} \mathrm{~m}^{3} / \mathrm{s}(1.9 \mathrm{cfm})$ over the pressure range of 1.0 to $101.3 \mathrm{KPa}$ ( 7.5 to 760 torr) and will thus be able to pump the coolant lines down to the FC-75 loading pressure of $1 \mathrm{KPa}$ in less than a minute. The TriVac E T1-21111233 requires a $120 \mathrm{~V}$, single-phase electrical input at $60 \mathrm{~Hz}$.

\section{Coolant Tubing and Pressure Relief Valve}

The segments of coolant tubing to be attached to the motherboard will be fabricated from 0.25 in. diameter, 0.020 in. wall, aluminum tubing (AL-1100) to the geometric specifications stated in the MVD technical drawing (No. 126Y-267683). A local vendor, Hand Precision Machining, Inc., built a successful prototype used in the experimental LDO cooling tests [3]. Consequently, they should be employed to fabricate the coolant tubes for the final design. 
A stainless steel proportional pressure relief valve was incorporated into the design should the unlikely event of a high line pressure situation developing (i.e., boiling of the FC-75). The spring chosen for the relief valve listed in Table 10 has a cracking pressure between 50 and 350 psig. For the MVD liquid cooling system, this valve should be set at its lower cracking pressure of 50 psig. The valve should be mounted so that its discharge end points away from potential operators.

\section{Instrumentation}

A DP41-TC-A temperature monitor with a KMTSS-125G-6, type-K thermocouple probe from Omega was chosen to provide temperature measurements of the FC-75 from the liquid cooling system after exiting the chiller unit. This temperature monitor has a linear direct voltage output of 0 to $5 \mathrm{Vdc}$ for temperature and has an optional RS port for computer communications. The thermocouple probe is placed in a stainless steel (316SS) watertight sheath that has a $152.4 \mathrm{~mm}(6.0 \mathrm{in}$.$) length and a 3.2$ $\mathrm{mm}(0.125 \mathrm{in}$.) diameter. A compression fitting will be required to mount the probe in the center of the FC-75 flow line downstream of the chiller. The monitor will require a direct current input voltage of $120 \mathrm{Vac}$ for operation.

\section{Tubing, Fittings, and Insulation}

Accurate Plastics Inc., and Albuquerque Valve and Fitting have been chosen as the suppliers of tubing and fittings. Accurate Plastics can provide both rigid and flexible tubing for the vacuum lines, and Albuquerque Valve and Fitting has aluminum and copper tubing for the coolant lines. Albuquerque Valve and Fitting can also supply the 
compression fittings needed for installing and connecting the coolant lines and instrumentation. Grainger, a vendor for industrial equipment and supplies, has a large variety of insulation tapes and pipe sleeves. Fire code criteria for these insulation materials are specified by the vendor. Becaùse the exact placement of components and routing of coolant lines has not yet been determined, the precise amount of tubing, fittings, and insulation caunot be determined at this point in time.

\subsubsection{Safety Measures}

Several safety measures have been included in the final liquid cooling system design to ensure proper operating performance of the low dropout voltage regulators. These measures are as follows:

- An upper design goal temperature limit of $40^{\circ} \mathrm{C}$ for the LDOs was used to base the cooling requirements for the liquid cooling system. This design goal is conservatively $85^{\circ} \mathrm{C}$ below the maxinum $\mathrm{LDO}$ operating temperature limit of $125^{\circ} \mathrm{C}$.

- FC-75 was chosen as the working fluid for the liquid cooling system. This liquid has an extremely low dielectric constant $\left(1.86\right.$ at $\left.25^{\circ} \mathrm{C}\right)$, which significantly reduces the chances of electrical shortages should the liquid leak out onto electrical components. In addition, $\mathrm{FC}-75$ has a boiling point of $102^{\circ} \mathrm{C}$ (at standard pressure) that is sufficiently high enough to prevent boiling in the present system. FC-75 is a fluorocarbon fluid that is nonflammable, nonexplosive, nontoxic, compatible with metals, plastics, and elastomers, and is nondamaging to the stratospheric ozone layer (no CFCs). 
- The liquid flow loop was designed with a pressure relief valve to prevent excess pressure buildup should a two-phase condition develop in the coolant lines (i.e. breakdown of the pump leading to heat buildup and boiling of the FC-75).

- The liquid chiller's cooling and pumping capacities were oversized to allow for abnormal operating conditions.

\subsubsection{System Operation}

The setup and operation of the LDO liquid cooling system will proceed as follows:

1. The chiller's reservoir is filled with FC-75.

2. The inlet and outlet valves between the coolant lines and the liquid chiller are closed to the chiller, and the valves between the MVD and vacuum pump are opened.

3. The vacuum pump is allowed to evacuate the coolant lines, a process that should take roughly a minute or so. After evacuation of the coolant lines is completed, the valves between the vacuum pump and the coolant lines are closed and the pump lines vented.

4. The reservoir fill cap must be opened to the environment to balance the pressure in the reservoir during loading of the coolant lines. Next, the valves between the chiller reservoir and the coolant lines are slowly opened to allow the FC-75 to flow from the reservoir and load the coolant lines. Upon completion of this step, there should be no significant air pockets in the coolant lines. Finally, the reservoir should be topped off with FC-75 and sealed.

5. The liquid chiller is activated and adjusted manually until the FC-75 liquid delivery temperature of $5^{\circ} \mathrm{C}$ is achieved, as determined with the aid of the temperature probe 
and display. This maly require setting the fluid reservoir temperature on the liquid chiller a few degrees below the desired delivery temperature. 


\subsection{Action Items}

The following is a list of items that still need to be addressed to some degree before the final design and installation of the MVD cooling systems are complete.

\section{General}

- Corrective action must be taken for all of the design and assembly flaws that were noted during the various prototype tests $[1,2,3,4]$. These flaws, corrective suggestions, and all current corrective actions are summarized in the Appendix.

- The placement of all cooling system components and routing of all cooling system flow and power lines must be completed. In addition, all pipe lengths, required fittings, mounting and/or securing methods, etc., must be determined. The current design calls for placing the main cooling components (chillers, pumps, heat exchangers, etc.) in the PHENIX outrigger supports shown in Figure 11. Caution must be exercised during installation to ensure that excessive amounts of tubing or fittings (beyond that used in the prototypes $[1,2,3,4]$ ) are not used that could greatly increase the pressure drop in the flow lines.

- Insulation for all of the coolant and airflow lines must be selected and included in the designs for the three MVD cooling systems. This will enhance the cooling 


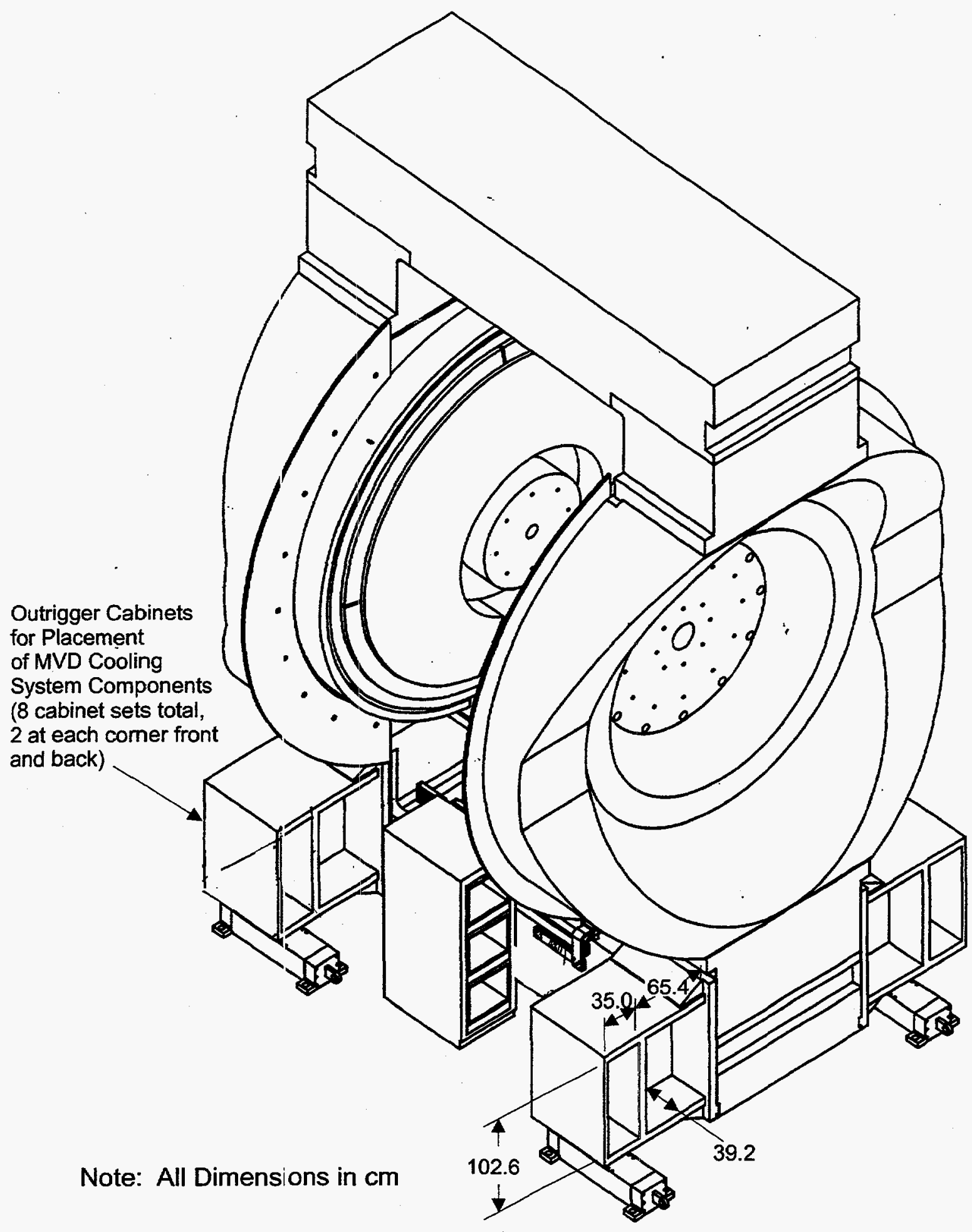

Figure 11. Schematic diagram of the PHENIX detector superstructure and outriggers. 
performance of the systems and prevent unwanted condensation buildup on the outside of the lines.

- A proper water and antifreeze mixture must be prepared as the working fluids in the water chillers of the primary and secondary air cooling systems. This precaution is necessary to prevent freezing of the working fluid and associated line blockage.

- Correct input supply voltages must be supplied to the monitoring instrumentation.

- A software subroutine must be written to convert the mean air velocity measurements to air volumetric flow rates for the primary and secondary air cooling systems. The air volumetric flow rate is simply the mean air velocity multiplied by the crosssectional area of the pipe at the location of the monitoring probe.

- Correct specification of the humidity (relative versus specific) operating conditions must be made. A specific humidity operating range is given in this report. This must be correctly converted to a corresponding relative humidity range for the particular operating temperature for correct programming and interpretation of the humidity sensors and controllers (which operate on a temperature compensated relative humidity scale).

- A backup fan unit and water chiller should be purchased for the air cooling systems. These backup units should be large enough to be able to handle the operation requirements of either system should a failure in one of the main components occur.

- Final costs for the MVD cooling systems can only be completed following the final designs of the air-to-water heat exchangers, dehumidifier unit, and tubing/fitting layouts. The current total cost estimation of $\$ 31,217$ does not include tax and 
shipping costs, backup systems, or costs for nonfinalized components (i.e., heat exchangers, tubing, etc.).

\section{Primary Air Cooling System (MCMs)}

- The final design including drawings and the selection of a fabrication vendor must be completed for the air-:o-water heat exchanger.

\section{Secondary Air Cooling System (Enclosures)}

- A final design including drawings and the selection of a fabrication vendor must be completed for the air-1:0-water heat exchanger, dehumidifier unit, and drain reservoir.

- Correct operation of the liquid level and humidity sensors/controllers must be verified by properly testing before final installation. This is a fairly complex system and caution must be exercised to ensure that the humidity controller is correctly programmed and conrected to the power supply of the dehumidifier unit's chiller. In addition, the liquid level sensor/controller must be properly connected to the solenoid drain and air relief valves in order to remove condensation buildup in the dehumidifier unit.

- The operating range for the specific humidity of the MVD enclosures must be specified. The curren: range is 0.0035 to $0.007 \mathrm{~kg} \mathrm{H}_{2} \mathrm{O} / \mathrm{kg}$ air (values at $\mathrm{BNL}$ ). The controller for the dehumidifier unit will operate on relative humidity. Consequently, the relative humidity range that corresponds to the above specific humidity range must be specified for the controller. This relative humidity range will depend on the operating temperature of the enclosure (i.e., between $10^{\circ} \mathrm{C}$ and $20^{\circ} \mathrm{C}$ ). Thus, if the 
operating temperature is $10^{\circ} \mathrm{C}$, the operating relative humidity range for the enclosure will be $40 \%$ to $95 \%$. A psychrometric chart [Table B.13b in reference 10] gives the relationship between relative humidity, specific humidity, and dry-bulb temperature.

\section{Liquid Cooling System (LDOs)}

- The selection of a fabrication vendor must be completed for the flat aluminum coolant tubes to be attached to the motherboard.

- A conductive epoxy must be selected for attaching the LDOs and coolant tubing to the motherboards.

- The FC-75 liquid for the LDO cooling system has been ordered from $3 \mathrm{M}$ and should be delivered to TA-3, Building 218, LANL, sometime in October, 1997.

- The FC-75 liquid reservoir must be positioned within $5.8 \mathrm{~m}(19.0 \mathrm{ft})$ vertically beneath the highest point on the liquid cooling system line in the MVD motherboard. This will ensure that the FC-75 can be drawn all the way through the coolant lines from the reservoir by evacuating the lines (recall that $\Delta P=\rho g h$ ). 


\section{References}

[1] Bernardin, J. D., Bosze, E., Clark, D., Boissevain, J., and Simon-Gillo, J., 1997, "An Experimental Investigation of an Air Cooling Scheme for the Multichip Modules of the Multiplicity and Vertex Detector," Technical Report LA-13320MS, Los Alamos National Laboratory, Los Alamos, NM 87545.

[2] Bernardin, J. D., Bosze, E., Boissevain, J., and Simon-Gillo, J., 1997, "An Experimental Investigation of Airflow Induced Vibrations within the Multiplicity and Vertex Detector," Technical Report LA-13319-MS, Los Alamos National Laboratory, Los Alamos, NM 87545.

[3] Bernardin, J. D. and Bosze, E., 1997, “An Experimental Investigation of a Liquid Cooling Scheme for the Low Dropout Voltage Regulators of the Multiplicity and Vertex Detector," Technical Report, Los Alamos National Laboratory, Los Alamos, NM 87545.

[4] Cunningham, R., Bernardin, J. D., and Simon-Gillo, J., 1997, "An Experimental Investigation of an Environmental Control Scheme for the Enclosure of the Multiplicity and Vertex Detector," Technical Report, Los Alamos National Laboratory, Los Alamos, NM 97545.

[5] Incropera, F. P. and DeWitt, D. P., 1987, "Fundamentals of Heat and Mass Transfer," $2^{\text {nd }}$ ed., John Wiley and Sons, Inc., New York.

[6] Lindeburg, M. R., 1984, "Mechanical Engineering Review Manual," $7^{\text {th }}$ ed., Professional Engineering Registration Program, San Carlos, CA.

[7] Scott, A. W., 1974, "Cooling of Electronic Equipment," John Wiley and Sons, Inc., New York.

[8] van Heck, H., 1997, "MVD Mechanical Tolerance Studies," PHENIX Technical Note, PHENDX-MVD-97-24, PHENIX Note \#307, Los Alamos National Laboratory, Los Alamos, NM, 87545.

[9] Shames, I. H., 198?, "Mechanics of Fluids", $2^{\text {nd }}$ ed., McGraw-Hill Book Co., New York.

[10] Reynolds, W. C. and Perkins, H. C., 1977, "Engineering Thermodynamics," $2^{\text {nd }}$ ed., McGraw-Hill ]3ook Co., New York. 


\section{List of Vendors}

Accurate Plastics (Western U.S. Sales)

P.O. Box 206

Pioneer, CA 95666

Fax: 914-476-0527

Phone: $800-431-2274$

Albuquerque Valve and Fitting Co.

2451 Alamo SE

Albuquerque, NM 87106

Phone: 505-842-0213

Fax: 505-843-6078

FTS Systems

3538 Main St.

P.O. Box 158

Stone Ridge, NY 12484-0158

Fax: 914-687-7481

Phone: $800-824-0400$

Technical support phone: 914-687-0071

www.ftssystems.com

Grainger

3901 Osuna Rd, NE

Albuquerque, NM 87109-4431

Fax: 505-345-9600

Phone: 505-345-8631

Hand Precision Machining, Inc.

127 Eastgate Dr.

Los Alamos, NM 87544

505-662-9001

Leybold Vacuum Products, Inc.

Albuquerque, NM

505-255-5660

Lytron, Inc.

55 Dragon Court

Woburn, MA 01801

Fax: 617-935-4529

Phone: 617-933-7300 
Omega Engineering, Inc.

P.O. Box 2284

Stamford, CT 06906-028.4

Fax: 1-800-848-4271

Sales phone: $1-800-826-6342$

Technical support phone: $1-800-872-9436$

Sonic Air Systems, Inc.

1150 West Central Ave.

Brea, CA 92821

Fax: 714-255-8366

Phone: $800-827-6642$

Sonic Air Systems, Southwest Regional Distributor Republic Sales \& Manufacturing Co.

5131 Cash Rd.

Dallas, TX 75247

Fax: 214-631-3673

Phone: 214-631-8070

3M Electronic Products Division

6801 River Place Blvd.

Austin, Texas 78726-9000

Sale's Contact: Ron Goff's Phone: 512-984-3359

General sales phone: $800-328-0411$

General sales fax: 800-932-9373

Technical support phone: $800-833-5045$ 
Appendix - Design/Assembly Problem Summary 


\section{Problems Observed in the Design Aspects of the MVD Cooling Systems}

Begun (6-19-97), Last Updated (10-7-97)

Primary Air Cooling System

\begin{tabular}{|c|c|c|c|}
\hline Component & Problem & Proposed Solution & Action Taken \\
\hline $\begin{array}{l}\text { Lucite inlet/outlet } \\
\text { Adapters }\end{array}$ & $\begin{array}{l}\text { Clearance fit between the Lucite adapters and } \\
\text { rings is not good enough to form an air-tight seal } \\
\text { and/or attach the air lines to the MVD endplates. }\end{array}$ & $\begin{array}{l}\text { Use an epoxy or glue to attach the Lucite adapters to } \\
\text { the Lucite rings (on the endplates) to hold the } \\
\text { adapters in place and form a tight seal. }\end{array}$ & Tolerances tightened. \\
\hline $\begin{array}{l}\text { Lucite rings in end } \\
\text { plates }\end{array}$ & $\begin{array}{l}\text { Clearances between the Lucite ring and the } \mathrm{D}- \\
\text { rings on the endplates are insufficient for } \\
\text { allowing correct attachment of the Lucite } \\
\text { adapters and Rohacell plenum flow diverters. }\end{array}$ & $\begin{array}{l}\text { Move Lucite ring location approximately } 1 / 8^{\text {th }} \text { in. } \\
\text { away from the D-ring, leaving sufficient clearance } \\
\text { for the Lucite adapters and Rohacell plenum flow } \\
\text { adapters. }\end{array}$ & $\begin{array}{l}\text { Adapter boss diameter was } \\
\text { reduced. }\end{array}$ \\
\hline $\begin{array}{l}\text { Rohacell plenum } \\
\text { flow diverters } \\
\text { (connect to Lucite } \\
\text { rims) }\end{array}$ & $\begin{array}{l}\text { Because of the recession in the flow diverters for } \\
\text { the end-most horizontal Rohacell plenum pieces, } \\
\text { interference with the capton cables exiting these } \\
\text { end plenum pieces may result. Holes existed } \\
\text { between the flow diverter and radial Rohacell } \\
\text { plenum that allowed excessive air leakage } \\
\text { (possible machining/assembly error). }\end{array}$ & $\begin{array}{l}\text { Recheck all dimensions and clearances on the } \\
\text { engineering drawings. Make dimensional changes if } \\
\text { necessary. }\end{array}$ & $\begin{array}{l}\text { Total redesign of flow diverters } \\
\text { made. }\end{array}$ \\
\hline $\begin{array}{l}\text { Horizontal plenum } \\
\text { springs }\end{array}$ & $\begin{array}{l}\text { Spring material is not needed to hold plenum in } \\
\text { compression and is not recommended because } \\
\text { the proposed material would leak a significant } \\
\text { amount of air. }\end{array}$ & Leave out any intended spring material. & Spring material removed. \\
\hline $\begin{array}{l}\text { Radial Rohacell } \\
\text { upper plenum } \\
\text { adapters (connect } \\
\text { horizontal support } \\
\text { flow passage to } \\
\text { radial plenum) }\end{array}$ & $\begin{array}{l}\text { Air hole in the upper Rohacell radial plenum } \\
\text { fixture did not line up with corresponding } \\
\text { opening in the radial Rohacell Plenum. Suspect } \\
\text { the aluminum tube (air line) coming off of the } \\
\text { cross-support member was too long. Had to drill } \\
\text { the hole in the Rohacell fixture deeper to allow } \\
\text { air holes to line up. }\end{array}$ & $\begin{array}{l}\text { Recheck all dimensions and clearances on the } \\
\text { engineering drawings. Make dimensional changes if } \\
\text { necessary. }\end{array}$ & Total redesign of adapters made. \\
\hline $\begin{array}{l}\text { Radial Rohacell } \\
\text { plenum }\end{array}$ & $\begin{array}{l}\text { No means of fastening the two halves of the } \\
\text { radial plenum together. Also, no means of } \\
\text { attaching the assembled plenum to the } \\
\text { motherboard. }\end{array}$ & $\begin{array}{l}\text { Use nylon screws (8-32s), nuts, and washers to attach } \\
\text { the two Rohacell plenum pieces together and also } \\
\text { fasten them to the motherboard. In the radial } \\
\text { direction away from the beam line, screws should be } \\
\text { spaced on base circle radii immediately inside and } \\
\text { immediately outside the edges of the radial MCMs. } \\
\text { In addition, the screws should be placed between }\end{array}$ & Fasteners included in the design. \\
\hline
\end{tabular}




\begin{tabular}{|l|l|l|l|}
\hline Motherboard & $\begin{array}{l}\text { No means of attaching motherboard to endplates } \\
\text { or to Rohacell holding MCMs. }\end{array}$ & $\begin{array}{l}\text { each radial MCM in the circumferential direction. } \\
\text { Several nylon screws and Rohacell spacers are } \\
\text { the attached radial MCM plenum) relative to the } \\
\text { endplates. }\end{array}$ & Fasteners included in the design. \\
\hline $\begin{array}{l}\text { MVD Mounting } \\
\text { Connectors }\end{array}$ & $\begin{array}{l}\text { Brass ring jams and rotates with nut assembly. } \\
\text { Need a special tool to hold brass ring. Makes } \\
\text { installation difficult. }\end{array}$ & Redesign connectors using a quick-release system. & $\begin{array}{l}\text { Connectors redesigned with a } \\
\text { quick-release system. }\end{array}$ \\
\hline
\end{tabular}

\section{Secondary Air Cooling System}

\begin{tabular}{|c|c|c|c|}
\hline Component & Probiem & P̈roposed Solution & Corrective Action Taken \\
\hline $\begin{array}{l}\text { Lucite inlet/outlet } \\
\text { adapters }\end{array}$ & $\begin{array}{l}\text { The diameter of the Lucite adapters is too small } \\
\text { and leads to a high pressure drop. In addition, the } \\
\text { Lucite fitting on the MVD side of the endplate } \\
\text { slips and can move into the MVD, coming } \\
\text { in contact with the motherboard and hence cutting } \\
\text { off the air flow. Calculated pressure drop for air } \\
\text { flow rate of } 0.01 \mathrm{~m}^{3} / \mathrm{s} \text { is } 0.54 \text { psi. This is a } \\
\text { HUGE } \Delta \mathrm{P} \text { for an air blower. }\end{array}$ & $\begin{array}{l}\text { Make larger adapters, at least } 1.50 \text { in. inside } \\
\text { diameter or equivalent cross-sectional area if a } \\
\text { circular fitting is not allowed because of placement } \\
\text { availability. If no change is made, a very large air } \\
\text { blower must be used to overcome the pressure drop. } \\
\text { Make sure that the fitting stays connected to the } \\
\text { endplate and cannot slip inward. } \\
\text { Calculated pressure drop for an airflow rate of } 0.01 \\
\mathrm{~m}^{3} / \mathrm{s} \text { is } 0.012 \text { psi, which is very reasonable. }\end{array}$ & $\begin{array}{l}\text { Adapters left as is. Larger air } \\
\text { blowers with sufficient flow } \\
\text { capacity and power to overcome } \\
\text { the large pressure drop were } \\
\text { selected for final design. }\end{array}$ \\
\hline
\end{tabular}

\section{Liquid Cooling System}

\begin{tabular}{|c|c|c|c|}
\hline Component & Problem & Proposed Solution & Corrective Action Taken \\
\hline Coolant tube & $\begin{array}{l}\text { No mounting scheme called out for fastening } \\
\text { tube to motherboard. }\end{array}$ & $\begin{array}{l}\text { Use small U-shaped clamps that fasten to } \\
\text { motherboard with screws or use a thermally } \\
\text { conducting epoxy. }\end{array}$ & \\
\hline LDOs & No mounting or insulation schemes for LDOs & $\begin{array}{l}\text { Back sides of LDOs should be insulated with } \\
\text { Rohacell to prevent heat leakage to rest of system. } \\
\text { LDOs can be mounted with a thermally conducting } \\
\text { epoxy. }\end{array}$ & \\
\hline $\begin{array}{l}\text { Thermal bridge from } \\
\text { LDOs to coolant tub }\end{array}$ & $\begin{array}{l}\text { Currently no design of a thermal bridge from the } \\
\text { LDOs to the coolant tube. }\end{array}$ & $\begin{array}{l}\text { Thermal vias in the motherboard have been } \\
\text { proposed. }\end{array}$ & $\begin{array}{l}\text { Thermal vias designed and } \\
\text { successfully tested. }\end{array}$ \\
\hline Coolant & Water is a potential risk to electronics & Use a dielectric coolant in place of water & $\begin{array}{l}\text { Change working fluid from water } \\
\text { to FC-75 }\end{array}$ \\
\hline
\end{tabular}




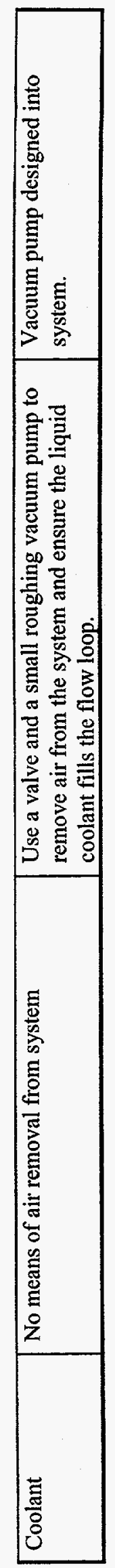

